\section{IJ§ER}

ISSN: 2149-5939
International Journal of Social Sciences and Education Research

Online, https://dergipark.org.tr/tr/pub/ijsser

Volume: 7(4), 2021

\title{
Fakültemizi ne kadar tanıyoruz? Örgüt kültürüne ilişkin bir araştırma
}

\author{
How much do we know our faculty? A research on organizational culture
}

\author{
Sibel Güven ${ }^{1}$ ve Merve Uçar ${ }^{2}$
}

${ }^{1}$ Doç. Dr. Çanakkale Onsekiz Mart Üniversitesi, Eğitim Fakültesi, Temel Eğitim Bölümü, Çanakkale, Türkiye, e-mail: s_guven@comu.edu.tr ORCID: https://orcid.org/0000-0003-4550-7297

${ }^{2}$ Doktora öğr., Çanakkale Onsekiz Mart Üniversitesi, Eğitim Fakültesi, Temel Eüitim Bölümü, Çanakkale, Türkiye, e-mail: merveucar7@gmail.com ORCID: https://orcid.org/0000-0002-9561-1159

\begin{tabular}{|c|c|}
\hline Makale Bilgisi & $\ddot{O} z$ \\
\hline $\begin{array}{l}\text { Gönderilme: } 3 \text { Ekim } 2021 \\
\text { Düzeltme: } 27 \text { Ekim } 2021 \\
\text { Kabul: } 27 \text { Ekim } 2021 \\
\\
\text { Anahtar kelimeler: } \\
\text { Örgüt kültürü,, } \\
\text { Örgütsel semboller, } \\
\text { Yüksekögretim ögrencileri, } \\
\text { Durum çalışması }\end{array}$ &  \\
\hline
\end{tabular}

\begin{tabular}{|c|c|}
\hline Article Info & Abstract \\
\hline $\begin{array}{l}\text { Research Article } \\
\text { Received: } 3 \text { October } 2021 \\
\text { Revised: } 27 \text { October } 2021 \\
\text { Accepted: } 27 \text { October } 2021 \\
\text { Keywords: } \\
\text { Organizational culture, } \\
\text { Organizational symbols, } \\
\text { Higher education students, } \\
\text { Case study }\end{array}$ & $\begin{array}{l}\text { The study group of this research, which was carried out in order to reveal how much the 4th } \\
\text { year students of the faculty of education know about the faculties of education, within the } \\
\text { framework of the components of the organizational culture, consisted of } 141 \text { senior students } \\
\text { from the Faculty of Education of one of state university in Turkey. In this research, in which } \\
\text { the qualitative method was used, case study was preferred as the design. The data were } \\
\text { collected from the "How well do we know our Faculty of Education?" with open-ended } \\
\text { questions. The data were collected on the web through a questionnaire and Google forms. } \\
\text { Content analysis was used in the analysis of the data. The data coded with the "MAXQDA } \\
2020 \text { " package program was analyzed and presented in tables with percentage frequency } \\
\text { values. According to the results obtained from the research, the education faculty was de- } \\
\text { fined as a place that develops people in the process, is the basis of education and teaching, } \\
\text { and enlightens people to reach their goals. It was concluded that the faculty of education } \\
\text { met the expectations of teacher candidates in general terms and they related this to meeting } \\
\text { them in terms of teachers and education. On the other hand, they stated that the situation } \\
\text { they complained about the most in the education faculty they were in was the physical struc- } \\
\text { ture, and they did not know who the deans and vice deans of the faculty of education were, } \\
\text { their job descriptions and where their rooms were. }\end{array}$ \\
\hline
\end{tabular}

\footnotetext{
* Bu araştırma T.C. Çanakkale Onsekiz Mart Üniversitesi Lisansüstü Eğitim Enstitüsü Etik Kurulunun 04.05.2020 tarih ve 4/2020/72 kararı ile etik açından uygun bulunmuştur. Tüm sorumluluk yazarına aittir.
}

Bu araştırma Çanakkale Onsekiz Mart Üniversitesi Bilimsel Araştırma Projeleri Birimi (BAP) tarafindan desteklenen SBA2019-2934 nolu projesinin parçasıdır.

Kaynak göster: Güven, S. \& Uçar, M. (2021). Fakültemizi ne kadar tanıyoruz? Örgüt kültürüne ilişkin bir araştırma. International Journal of Social Sciences and Education Research, 7 (4), 403-426. DOI: https://doi.org/10.24289/ijsser.1004135 


\section{Giris}

Geniş anlamıyla örgüt; belirli amaçlar doğrultusunda kişilerin çabalarının uyumlu olarak sürdürüldüğü bir yönetim işlevi; amaç, insan, teknoloji boyutlarının etkileştiği bir sistem; kişiliğini belirleyen ve kendine özgü bir kültürü olan; işleri, mevkileri, çalışanları ve aralarındaki yetki ve iletişim ilişkilerini gösteren bir yapıdır. Örgütlerin hayatta kalmaları birçok dinamiği barındırmaları ile mümkün olmaktadır. Bu dinamiklerin en önemlisi şüphesiz kültürdür. Kültür, örgütleri saran toplumsal çevre şartlarının en önemli öğelerinden biridir, bu nedenle örgütlerin yaşama ve gelişmelerini geniş ölçüde etkiler. Örgüt kültürü örgüt gerçeğinin görülmesine imkân veren düşünsel bir yapı yani bir paradigmadır. Örgüt kültürü, "bir örgütün içindeki insanların davranışlarını yönlendiren normlar, davranışlar, değerler, inançlar ve alışkanlıklar sistemidir” (Dinçer, 1992, Güçlü, 2003). Örgüt kültürü, örgüt üyelerinin örgüte ve amaçlarına yönelik bağlllık geliştirmelerini sağlayan, örgütte yaşanan sorunların çözümüne yönelik yol gösterici bir nitelik taşıyan, örgüt üyelerinin örgütsel davranış biçimlerini algılamalarına ve çözümlemelerine yardımcı olan, örgütün amacını, vizyonunu değerleri, normları, ritüelleri, inanış biçimlerini, gelenekleri, törenleri, hikayeleri ve işgörenler arasındaki ilişkileri kapsayan bir üst kavram olarak değerlendirilebilir (Peterson ve Deal, 2009; Schein, 2010; Akt. Kılıç, 2014:99). Örgütsel kültür, her örgütün diğer örgütlerden kültürel olarak farklılı̆ıını ifade eder (Güney, 2001). Eldridge ve Crombie'ye göre bir örgütün kültürü, grup üyelerince paylaşılan normlar, değerler, inançlar, tutum ve davranışlardır. Her örgüt kendine has bir kültür ile var olmaktadır. Ve bu kültür yapısı ile diğer örgütlerden ayrılmaktadır. Kendine has derin bir kültüre sahip olan örgütlerden en önemlilerinden biri de eğitim fakülteleridir.

Çağdaş öğretmenlerin varlığı ve çabası ile yetiştirilebilecek olan iyi insanın her konu açısından donanımlı, ufku açık, bilgi birikimi yüksek, değişime, gelişime açık gibi özellikleri taşıması gerekmektedir. Böylece toplumların gelişmişlik düzeylerini belirleyen iki göstergeden biri olan yetişmiş insan gücü karşılanmış olacaktır. Çağdaş bir öğretmenin varlığı ise eğitim fakültelerinin sahip olduğu önemi daha da arttırmaktadır. Kaliteli bir eğitim, donanımlı bir eğitim kadrosu, fiziki yeterlilik yanında güçlü bir örgüt kültürü, güçlü bir vizyon ve olumlu bir iklim eğitim fakültelerinin sahip olması gereken özellikler arasında yer almaktadır. Eğitim fakülteleri hayatımızın her alanında var olan örgütlerden sadece biridir. Her örgüt hizmet verdiği alan ve taşıdığı amaçlara göre farklılık göstermektedir. Bu farkll1lk tören gelenek, görenek, değer ve kişilerle var olan ve örgütlerin kendi kültürlerini üretmeleri ile yakından ilişkilidir (Çelik, 2012). Hiçbir insan nasıl ki var olduğu kültürden kendini soyutlayamaz ona ayak uydurmak zorundadır örgütte var olan bireylerde belli bir kültürü kabul etmek ve kültürün gerektiği değer yargılarını kabul etmek zorundadırlar. Örgüt Kültürü, bir örgütü diğer örgütlerden ayıran, diğer örgüt üyeleri tarafindan paylaşılan bir anlam (değer) sistemini ifade eder. Örgüt kültürü, bir dizi sembol, değerler, normlar, inançlar, gelenekler, semboller, tören ve mitten oluşur. Bütün bunlar, örgütün inanç ve değerlerini çalışanlara aktarır (Ouchi, 1987:45). Steinhoff ve Owens (1989)' de örgüt kültürünün öğelerinin, örgüt tarihi, değerler ve inançlar, normlar, hikâyeler ve mitler, törenler ve kahramanlar, gelenek ve göreneklerden oluştuğunu belirtmiş̧ir. Örgüt kültürünün temel öğeleri değerler, normlar ve varsayımlardır. Diğer yandan, örgüt kültürünün görülebilen ifade biçimleri arasinda; seremoniler ve törenler, adetler (ritüeller), hikayeler, mitler, semboller, dil ve kahramanlar sayılabilir.

Değerler, örgütteki tüm bireylerin ortaklaşa inandığı ve paylaştı̆̆ı kurum kültürünün önemli bir öğesidir. Geniş anlamda değerler, kültürün daha çok gözle görülmeyen, öznel, içsel yönünü oluşturmaktadır. Normlar ise örgütsel kültür içinde davranışı etkileyen, sosyal sistemi kurumsallaştıran ve güçlendiren ögeler olarak tanımlamaktadırlar (Owens ve Steinhof, 1989). Varsayımlar, örgütlerde, çalışanların tutumlarını, dolaysıyla da günlük eylemlerinin somut sonuçlarını etkileyen en güçlü kültürel öğelerden biridir. Varsayımlar örgüt üyelerinin algı, düşünce, his ve davranışlarını yönlendirerek, onların örgütsel yaşama ilişkin taşıdıkları doğru-yanlış, anlamlı-anlamsız, olanakl1-olanaksız gibi ön kabullerini oluşturan tartı̧masız doğrulardır (Sabuncuoğlu ve Tüz, 1998; İpek, 1999). Seremoniler özel olaylardır. Bu özel olay sırasında örgüt çalışanları örgütsel kültürün bir parçası olan kahramanlara, mitlere ve sembollere ait kutlamalar yaparlar. Bu nedenle seremoniler, önemli kültürel normların ve değerlerin anıldığı ve sağlamlaştırıldığı olaylara örnek teşkil etmektedirler. Seremonilerin birçoğu, gelenekselleşmiş etkinlikler olarak tanımlanan törenleri kapsamaktadır (Özkalp ve Kırel, 2000; Çelik, 2000). Semboller ise örgüt kültürünü pekiştirmeye yardımcı olan maddesel niteliklerdir. Semboller, alanların ve binaların tasarımı ve fiziksel görünümü, mobilyalar, yönetici giysileri, örgüt tarafindan kullanılan logolar, ürün tasarımları, ambalajlar vb. sembollerdir (Terzi, 2000). Bu semboller iş görenlere kimin önemli olduğunu, üst yönetim tarafından arzulanan eşitlik derecesini ve uygun olan davranış tarzlarını (risk alan, tutucu, otoriter, katılımcı, bireyci, sosyal vb.) aktarır (Taş, 1999). Adetler, yazılı olmayan, sürekli tekrarlanan veya günlük örgütsel uygulamalarda görülen davranışlardır (Nelson ve Campbell, 1997). Hikâye ve efsaneler örgüt kültürü açısından önem taşıyan ve genellikle örgütün geçmişine yönelik olayların, biraz da abartılarak aktarılması sonucunda ortaya çıkan kültür taşıyıcılarıdır (Unutkan, 1995). Dil, bir iletişim aracı olmanın yanı sıra, kültürün de yapı taşlarından birini oluşturmaktadır. Örgüt 
dilini ancak, o örgütte çalışanlar anlayabilir ve kullanabilmektedir. Çalışanlar bu dili öğrenerek, kültürü kabul ettiklerini gösterirler. Böylelikle, kültürün korunmasına yardımcı olurlar (Terzi, 2000). Buna göre her örgütün kendine özgü olan dili içinde; argo ifadeler, deyimler, şakalar mecazlar, metaforlar, sloganlar sözel semboller yer almaktadır (Becerikli, 1999).

$\mathrm{Bu}$ araştırmada ise semboller üçe ayrılarak incelenmiştir. Bunlar; fiziksel, sözel ve işlevsel sembollerdir. Örgütsel yaşamda var olan semboller; örgütlerin logoları, mimarisi, eşyalar gibi fiziksel semboller, örgütte kullanılan dil, metaforlar, mizah ve anlatılan hikayeler, efsaneler, kahramanlar gibi sözel semboller ve örgütte düzenlenen törenler ve seremoniler gibi işlevsel semboller olarak karşımıza çıkmaktadır (Özoğlu, 2015).

Yükseköğretim kurumları, her yıl iç değerlendirme raporu hazırlamakta ve bu raporlar temel alınarak yükseköğretim kurumları beş yılda en az bir defa Yükseköğretim Kalite Kurulu tarafından yürütülen dış değerlendirme sürecine dâhil edilmektedirler. Yükseköğretim kurumlarının yönetim stratejileri, hedeflerin tutarlılığı, süreçlerin etkin yönetimi gibi unsurlar ile yöneticilerin kurumu sahiplenmesi, liderlik gücü ve motivasyonu gibi etkenler kurumların kalite güvence çalışmalarının başarısında önemli rol oynamaktadır. Bu süreçlerde sadece üniversite değil, alt birimler fakülteler, yüksekokullar ve akademiler de aktif olarak katılım göstermektedir. Özellikle fakülteler ve fakülte bileşenleri olarak akademisyenler ve öğrencilerin de bu çalışmalara katılması beklenmektedir. Ancak öğrencilerin araştırma sürecine dahil edilme oranı söz konusu 50 üniversite için \%14 civarıdır. Bu oldukça düşük bir orandır. Öğrencilerin karar alma süreçlerine katılımı ile ilgili farkındalık düzeylerinin artırılmasına yönelik çalışmaların ivedilikle başlatılması ve Fakülte/YO/ Enstitü/MYO yönetim kurulları ile Senato ve Yönetim Kurullarındaki öğrenci katılımı ve temsiliyetinin uygulamaya da geçirilmesi bu noktada büyük bir önem arz etmektedir. Kurumların misyonu doğrultusunda öğrencilerin eğitim, araştırma ve toplumsal katkı ile ilgili süreçlere de dâhil edilmesi teşvik edilmelidir (YDKG, 2017). Buradan hareketle yapılan bu araştırma eğitim fakültesi öğrencilerinin kendi fakültelerini ne kadar tanıdıklarını, fakültenin örgütsel kültürünü benimseme noktasında yöneticilerin, öğretim elemanlarının ne kadar yeterli olduğunu göstermesi açıısından büyük bir önem taşımaktadır. Araştırmanın amacı bu nedenle, eğitim fakültesi 4. sınıf öğrencilerin eğitim fakültelerini ne kadar tanıdıklarını örgüt kültürünün bileşenleri olan fiziksel, sözel ve işlevsel bileşenler çerçevesinde ortaya koymaktır. Bu genel amaca bağlı olarak şu sorulara yanıt aranmıştır:

1. Eğitim fakültesi son sınıf öğrencilerinin eğitim fakültesinin mimari ve fiziksel özelliklerine ilişkin görüşleri nelerdir?

2. Eğitim fakültesi son sınıf öğrencilerinin beklentilerini karşılayabilmekte midir?

3. Eğitim fakültesi son sınıf öğrencileri öğretim elemanları ne kadar tanımaktalar?

4. Eğitim fakültesi son sınıf öğrencileri fakülte ve bölüm yöneticilerini ne kadar tanımaktalar?

5. Eğitim fakültesi son sınıf öğrencileri eğitim fakültesinde bulundukları süre içinde gelişen olaylara ne kadar hakimler?

6. Eğitim fakültesi son sınıf öğrencileri eğitim fakültesini bir şeye benzetse bu ne olurdu?

\section{Yöntem}

$\mathrm{Bu}$ araştırma T.C. Çanakkale Onsekiz Mart Üniversitesi Lisansüstü Eğitim Enstitüsü Etik Kurulunun 04.05.2020 tarih ve 4/2020/72 kararı ile etik açından uygun bulunmuştur. Tüm sorumluluk yazarına aittir. Araştırmada araştırmanın amacına uygun olarak nitel yöntem, desen olarak ise durum çalışması tercih edilmiştir. Durum çalışmalarında genelleme yapmak yerine durumdan en mükemmel şekilde ne anlaşıldığının çalışılmasının tasarısı üzerinde vurgu yapılmaktadır (Denzin ve Lincoln, 1994). Bu araştırmada da örgüt kültürünün etkisinin anlaşılması adına eğitim fakültesi öğrencilerinin eğitim fakültesini ne kadar tanıdıkları ortaya konulmaya çalışılmıştır. Amaç genelleme yapmak olmamış, var olan durumun net bir şekilde ortaya çıkarılması amaçlanmıştır. Böylece ortaya çıkacak olan ürün, gelecek araştırmalar için daha detaylı olarak nelere odaklanmanın gerektiğinin keskin bir biçimde anlaşılmasına yardımcı olur. Kısaca, durum çalışmalarının gerçekte var olan durum karşısında neler olduğunu anlama, sistematik bir biçimde verileri toplama, analiz etme ve sonuçları ortaya koyma yoludur (Davey, 2009).

\subsection{Evren ve örneklem / çalışma grubu}

Araştırmanın çalışma grubunu bir devlet üniversitesinin eğitim fakültesinde öğrenim gören son sınıf öğrencilerinden araştırmaya gönüllü olarak katılan 141 kişi oluşturmuştur. Çalışma grubuna ait demografik özellikler tablo 1'de verilmiştir. 
Tablo 1. Katılımcıların demografik özelliklerine ilişkin bulgular

\begin{tabular}{lcc}
\hline Özellikler & $\mathrm{f}$ & $\%$ \\
\hline Cinsiyet & & \\
\hline Kadın & 104 & 73.76 \\
Erkek & 33 & 23.40 \\
\hline Ana Bilim Dalı & $\mathrm{f}$ & $\%$ \\
\hline Temel Eğitim & 68 & 48.23 \\
Türkçe ve Sosyal Bilimler Eğitimi & 48 & 34.04 \\
Eğitim Bilimleri & 14 & 9.93 \\
Matematik ve Fen Eğitimi & 6 & 4.26 \\
Güzel sanatlar eğitimi & 2 & 1.42 \\
\hline Fakültede bulunma süresi & & \\
\hline 1 & 10 & 7.09 \\
3 & 63 & 44.68 \\
2 & 22 & 15.60 \\
4 ve üzeri & 42 & 29.79 \\
\hline Toplam & 141 & 100 \\
\hline
\end{tabular}

Tablo 1'de görüldüğü gibi araştırmaya katılan 141 öğretmen adayının 104 tanesi kadın, 33 tanesi ise erkek katılımcılardan oluşmaktadır. \%73.76 orana denk gelen kadın öğretmen adaylarının, katılımcıların çoğunluğunu oluşturdukları söylenebilir. Katılımcıların çoğunluğunun \%48.23 oranında (f:68) Temel Eğitim ABD’de öğrenim gören öğretmen adayları olduğu, Türkçe ve Sosyal Bilimler Eğitiminden 48, Eğitim Bilimlerinden 14, Matematik ve Fen Eğitiminden 6 ve Güzel Sanatlar Eğitiminden 2 öğretmen adayının araştırmaya katılım gösterdiği belirlenmiştir. Tablo 1'de ayrıca araştırmaya katılan 141 öğretmen adayının 63 tanesinin 3 yıldır, 42 tanesinin ise 4 yıl ve üzeri, 22 tanesinin 2 yıldır, 10 tanesinin ise 1 yıldır bu fakültede bulunan katılımcılar oldukları görülmektedir.

\subsection{Veri toplama aracı ve verilerin geçerlik ve güvenirliğinin sağlanması}

Araştırmada “Eğitim Fakültemizi Ne Kadar Tanıyoruz?” Anketi kullanılmıştır. "Eğitim Fakültemizi Ne Kadar Tanıyoruz?" anketi araştırmacılar tarafından hazırlanmıştır ve 6 bölümden oluşmaktadır. Birinci bölüm kişisel bilgiler, ikinci bölüm eğitim fakültesinin mimari özellikleri, üçüncü bölüm öğretim elemanları, dördüncü bölüm yöneticiler, beşinci bölüm eğitim fakültesinde ..., ve altıncı bölüm ise eğitim fakültesini bir şeye benzetseniz ne olurdu? başlıkları ile birlikte toplamda anket 39 sorudan oluşmuştur. Soruların bir kısmı evet-hayır şeklinde bir kısmı ise öğrencilerin uzun cevaplar verecekleri şekilde düzenlenmiştir.

Anketin oluşturulmasından sonra anket 5 üçüncü sınıf öğrencisine gönderilmiş öğrencilerin anketi doldurması istenmiştir. Soruların açık ve anlaşılır olup olmadığının, verilen yanıtların sorulan soruların yanıtlarını yansıtıp yansıtmadığının belirlenmesi amacıyla, öğrencilerin cevapladıkları formların alanı eğitim yönetimi ve temel eğitim olan 2 öğretim elemanı tarafından incelenmesi istenmiştir. Öğretim elemanlarının dökümleri inceleyerek sorulan soruların açık ve anlaşılır olup olmadığını, ele alınan konuyu kapsayıp kapsamadığını ve gerekli olan bilgileri sağlama olasılığını da düşünerek, kontrol etmesi istenmiştir. Bu çalışmanın sonunda, soru maddelerinin geçerliği saptanmıştır. Bilindiği gibi nitel araştırmalarda iç geçerlik, araştırmacının ölçmek istediği veriyi, kullandığı araç ya da yöntemle gerçekten ölçüp ölçemeyeceğine ilişkindir (Yıldırım ve Şimşek, 2008).

Araştırmanın güvenirliğini sağlamak adına Uzman ve araştırmacı birbirinden bağımsız olarak görüşme kodlama anahtarına her bir soru için işaretleme yapmışlardır. Araştırmacı dışındaki bir kişinin analiz sürecinde yer alması ve sonuçların karşılaştırılması sonucunda \%80 oranında hem fikir sağlanması kodlamanın güvenirliğini sağlamaktadır (Büyüköztürk ve Diğerleri 2010). Görüşme sorularının güvenirlik analizi için Miles ve Huberman (1994)'ın formülü ile gerçekleştirilmiştir: 'Uzlaşma Yüzdesi = Görüş Birliği / (Görüş Birliği + Görüş Ayrılığı) x 100 " uygulanmıştır. Araştırmada görüşme sorularının güvenirlik ortalaması ise \%89,20 olarak hesaplanmıştır. Bu sonuç, \% 70’den yüksek olduğu için araştırma güvenilir kabul edilmiştir.

\subsection{Verilerin toplanmast ve analizi}

Araştırmada veriler ilgili uygulama izinlerinin ve etik izin başvurularının alınmasından sonra Google formlar aracılığı ile katılımcılara ulaştırılmıştır. Araştırmada gönüllülük esas alındığı için herhangi bir zorlama olmaksızın anketi dolduran öğrencilerin geri dönüşleri beklenmiştir. Anket 2020-2021 güz döneminde öğretmen adaylarına ulaştırışmış ve aynı dönem toplanan veriler analiz edilmiştir. 
Veriler analiz edilirken, oluşturulan tema ve alt temalar aracılı̆̆ı ile kodlanmıştır ve temalar etrafinda birleştirilerek anlaşılır kılınmışıır. Verilerin analizinde tümevarımsal bir yaklaşım benimseniştir. Veriler, tema ve kategoriler ile karşılaştırma yapılabilmesi için sayıya indirgenmiştir. Bu aşamada sistematik ve pratik bir analiz yapabilmek amacıyla yazılım kullanımı tercih edilmiştir. Kurulan hiyerarşik ilişkiler ile veriler sistematik ve hızlı bir şekilde kodlanmıştır. Analizin yapıllması için “MAXQDA 2020" paket programı kullanılmıştır. Kodlanan verilerin analizi yapılmış ve yüzde frekans değerleriyle tablolar halinde bulgularda sunulmuştur.

Tablolarda verilen katılımcı görüşleri ile kodlardan bahsetme durumları, kodlanmış ve kodlanmamış belgeler olarak tabloda yer alan değerlerde farklılık oluşturmaktadır. Bunun nedeni olarak kodun katılımcı sayısı bakımından bahsedilme sıklığı ve ilişkili kategorinin tablo istatistiklerinde kodlanma sıklığının farklılaşmasıdır. Öğretmen adaylarının aynı kategoride birden fazla koddan bahsettikleri değişkenlerde, kodlardan bahseden katılımcı sayısında artış belirirken, her katılımcı raporu, ilgili kategori için sadece bir kez kodlanmıştır.

\section{Bulgular}

Bu bölümde nitel verilerin analizi sonucu elde edilmiş bulgular sunulmuştur.

\subsection{Katılımcıların Eğitim Fakültesine yönelik beklenti değişkenine ilişkin görüşleri}

Araştırmada ilk olarak katılımcıların eğitim fakültesine yönelik beklentilerinin neler olduğu ele alınmış, bulgular tablo 2'de gösterilmiştir. Yüzdelik oranların birbiri içerisinde farklılaşmasının nedeni beklentisini karşıladığını belirten bazı öğretmen adaylarının aynı zamanda bazı yönlerden beklentilerinin karşılanmadı̆̆ını da belirtmiş olmalarıdır. Bu durum çakışan kodlar şeklinde detaylı şekilde incelenmiştir.

Tablo 2. Katılımcıların eğitim fakültesine yönelik beklenti değişkenine göre dağılımı

\begin{tabular}{lll}
\hline Eğitim fakültesine yönelik beklenti & $\mathrm{f}$ & $\%$ \\
\hline Karşıladı & 94 & 66.67 \\
$\bullet \quad$ Hocalar ve eğitim açısından karşıladı & 58 & 41.13 \\
• Fiziksel anlamda karşılladı & 11 & 7.80 \\
Karşılamadı & 72 & 51.06 \\
• Hocalar ve eğitim açısından karşılamadı & 29 & 20.57 \\
• Fiziksel anlamda karşıllamadı & 27 & 19.15 \\
\hline Toplam & 141 & 100 \\
\hline
\end{tabular}

Tablo 2 incelendiğinde, 94 öğretmen adayı, eğitim fakültesine yönelik beklentilerinin karşılandığını ifade etmişlerdir. \%66.67 orana denk gelen öğretmen adaylarının, beklentisini karşılamadığını belirten öğretmen adaylarına (\%51.06) oranla çoğunlukta olduğu görülmektedir. Tablo 2'ye göre beklentisini karşıladığını belirten 94 öğretmen adayından 58 'i hocalar ve eğitim yönünden karşıladığını, 11 'i ise fiziksel açıdan karşıladığını ifade etmiştir. Eğitim fakültesinin beklentilerini karşılamadığını belirten katılımcıların ise; 29 tanesinin hocalar ve eğitim açısından, 27 tanesinin ise fiziksel açıdan karşılamadığını belirttiğgi görülmüştür. Beklentisini karşıladığını belirten öğretmen adaylarından bazılarının görüşleri şu şekildedir;

k.9: Ĕ̌itim fakültesi beklentilerimi karşıladl. Her bölümün kendi sinıflarının olması, etkileşim bağlamında aktif bir fakülte.

\section{k.10: Çok isteyerek geldim ve eğitiminden oldukça memnunum}

k.59: Ĕgitim kalitesi açısından beklediğimden daha iyi karş̧ladı. Hocalarımız biz ögrencileri derste daha aktif kılacak şsekilde ders işliyorlar. Bu da öğrendiklerimizin kalıcı olmasını ve meslek hayatımıza daha iyi hazırlanmamizı sağllyor.

Beklentisini karşılamadığını belirten katılımcılardan bazılarının görüşleri şu şekildedir;

\section{k.3: Daha aktif olunur sanıyordum, etkinlik açısından yetersizdi}

k.14: Bambaşka bir dünyanın kapılarını açacağını umuyordum. Elbette bu beklentimi karşılamadı. Vasat hocalar, yalnızca kadro tahsisi için açılmış dersler bu durumu etkileyen değişkenler arasında.

k.26: Öncelikle ögrencilerin ve ögretmenlerin otoparkları ayrı olmasl, ögretmenler fakülte önünde daha güvenli bir noktada araçların park ederken, ögrenciler hemen girişte solda ağaçların altında park ediyor, orayı izleyen ufak bi güvenlik kamerast dahi yok. Motorumun aynaları 2 kere çalınd 
k.131: Kampüs havası yok olmadiğı için ilk başta kendimi dershaneye gider gibi hissediyordum yani en azından bahçede vakit geçirilebilecek alan beklerdim lakin o da yok ama yine de konumunu seviyorum, eğitim olarak ortalama olduğunu düşünüyorum

Şekil 1. Kod birlikte oluşturma modeli çakışan kodlar: eğitim fakültesine yönelik beklenti değişkenine göre dağılımı

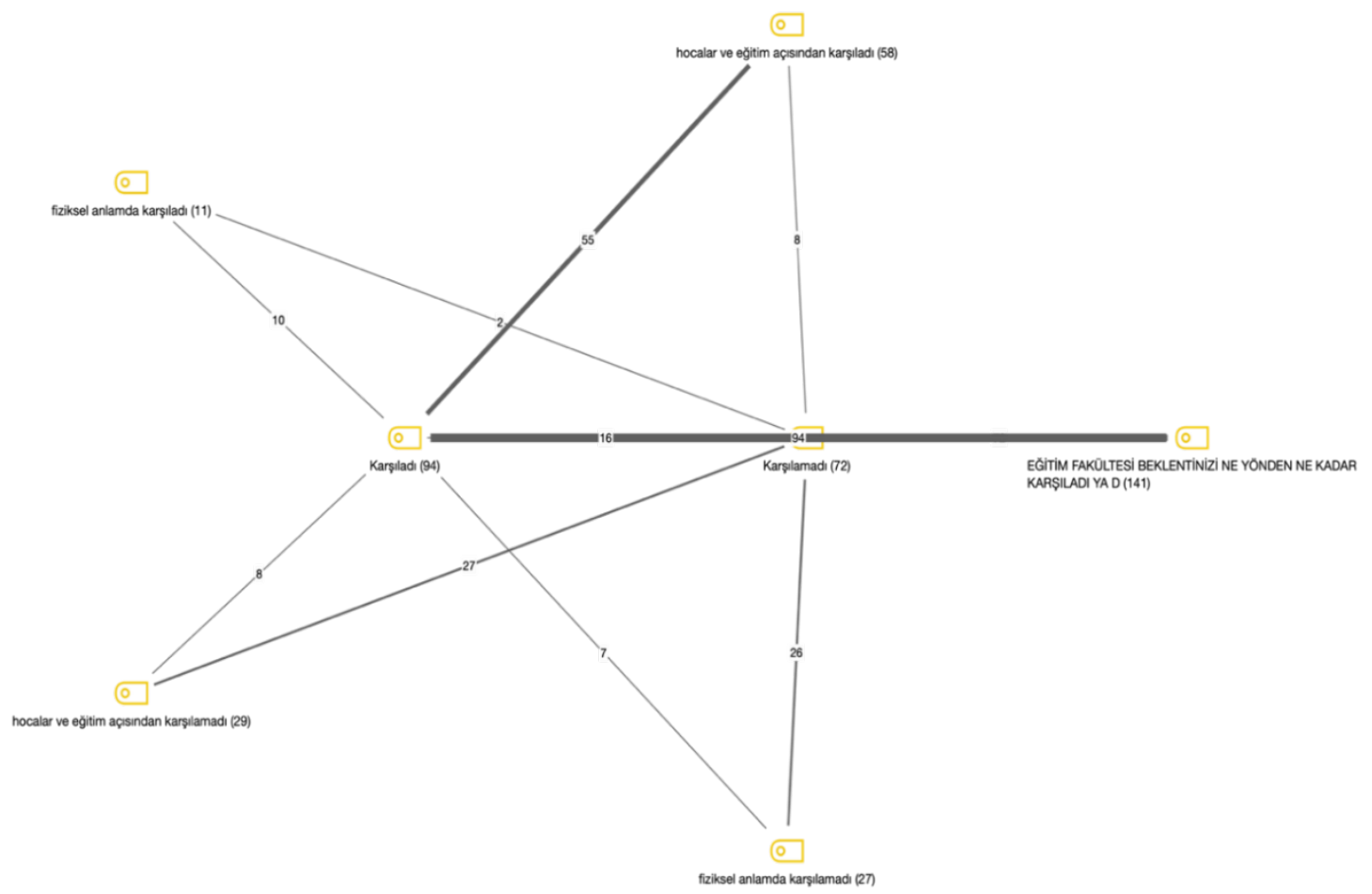

Şekil 1 incelendiğinde; beklentisini karşılamadığını söyleyen 72 öğretmenden 16 tanesinin aynı zamanda farklı yönlerden de beklentisini karşıladığını belirttiği böylece hem karşıladı hem de karşılamadı şeklinde görüş belirttiği tespit edilmektedir. Şekle göre beklentisini hocalar ve eğitim açısından karşıladığını belirten 58 öğretmenden 8 tanesinin aynı zamanda beklentimi karşılamadı şeklinde de görüş belirttikleri bulgusuna ulaşılmaktadır.

Beklentisini hem karşıladığını hem de karşılamadığını belirten katılımcılardan bazılarının görüşleri şu şekildedir;

K12. Eğitim fakültesi eğitim açısından beklentimi karşıladı fakat sınıfların küçük/dar olması dolayısıyla beklentimi karşılamadı.

k.37: Arkadaşlık bağları açısından karşıladı eğitim alanında bazı hocaların yeterliliği karşılamadı

k.66: Sosyal faaliyetler, konferanslar ve etkinlikler konusunda yetersizdi fakat ögrretmenlerimizin bilgisi ve ilgisi her zaman çok güzeldi

k.76: Mikroöğretim anlamında beklentimi karşıladı fakat her öğretmen uygulamayı ön planda tutmadı. Yaparak, yaşayarak ögretim için ögrenmek gerek önce. Öğretmenler de öğrenciler gibi farkl tabiki de fakat çă̆daş eğitimi savunup derslerin \%80 ini geleneksel işleyen ögretmenlerimiz de oldu. (Öğrenciyi sürece dahil etme konusunda)

k.83: Okul akademisyenlerinin öğrenciye verdiği değer açısından beklentimi karşılasa da okulun fiziki yapıstnın beklentimin altında olduğunu düşünüyorum.

k.113: Yüz yüze eğitim oldukça verimli iken online eğitimden memnun değilim.

Araştırmada ikinci olarak öğretmen adaylarının fakültenin rengini, kat sayısını giriş kapılarının yerini bilip bilmeme durumlarına ilişkin görüşleri alınmış, tablo 3' de gösterilmiştir. Tablo 3'e göre, araştırmaya katılım gösteren 141 öğretmen adayından 120 tanesinin fakültenin rengini bildiğini belirttiği görülmektedir. Öğretmen adaylarından 21'i ise eğitim fakültesinin rengini bilmemektedir. Araştırmaya katılım gösteren öğretmen adaylarının 124 tanesinin bulundukları eğitim fakültesinin kat sayısını bildiği, 17'sinin ise eğitim fakültesinin kaç katlı olduğu 
hakkında "bilmiyorum" şeklinde görüş belirttiği; yine 130 tanesinin fakültenin giriş kapılarının yerini bildiği, 11 ’inin ise eğitim fakültesinin giriş kapıları hakkında bilgi sahibi olmadığı görülmüştür.

Tablo 3. Öğretmen adaylarının fakültenin rengini, kat sayısını giriş kapılarının yerini bilip bilmeme durumlarına ilişkin görüşleri

\begin{tabular}{lllll}
\hline & \multicolumn{2}{c}{ Biliyorum } & \multicolumn{2}{c}{ Bilmiyorum } \\
& f & $\mathbf{\%}$ & f & \% \\
\hline Eğitim fakültesinin rengini & 120 & 85.10 & 21 & 14.81 \\
Eğitim fakültesinin kat sayısını & 124 & 87.94 & 17 & 12.05 \\
Giriş kapılarının yerini bilme & 130 & 92.20 & 11 & 7.80 \\
\hline
\end{tabular}

Araştırmada katılımcıların eğitim fakültesinde kullanılan en belirgin eşyayı bilme durumları da sorulmuş, bulgular tablo 4'de gösterilmiştir.

Tablo 4. Katılımcıların eğitim fakültesinde kullanılan en belirgin eşyayı bilme durumları

\begin{tabular}{lll}
\hline Binada kullanılan en belirgin eşyalar & $\mathrm{f}$ & $\%$ \\
\hline Binadaki ve koridordaki eşyalar & 89 & 63.12 \\
Sinıftaki eşyalar & 41 & 29.08 \\
Bilmiyorum & 19 & 13.48 \\
\hline Toplam & 141 & 100 \\
\hline
\end{tabular}

Binada kullanılan en belirgin eşyaların ne olduğu konusunda görüş belirten 89 öğretmen adayının bu eşyaların bina ve koridordaki eşyalar (panolar, asansör, merdivenler, oturma alanları, saksılar...) olduğunu, 41 öğretmen adayının bu eşyaların sınıf içerisindeki eşyalar (akıllı tahta, sıralar...) olduğunu belirttikleri Tablo 4 'de görülmektedir. Tablo 5'de ise katılımcıların eğitim fakültesinde kullanılan en belirgin araç ve gereçleri bilme durumları verilmiştir.

Tablo 5. Katılımcıların eğitim fakültesinde kullanılan en belirgin araç ve gereçleri bilme durumlarına göre dağılımı

\begin{tabular}{lll}
\hline Binada kullanılan araç gereçler & f & $\%$ \\
\hline Sinıf araç gereçleri & 68 & 48.23 \\
Binadaki ve sınıftaki araç gereçler & 63 & 44.68 \\
Bilmiyorum & 22 & 15.60 \\
\hline Toplam & 141 & 100 \\
\hline
\end{tabular}

Tablo 5 incelendiğinde binada kullanılan en belirgin araç ve gereçlerin ne olduğu konusunda görüş belirten 63 öğretmen adayının bu eşyaların bina ve koridordaki eşyalar (panolar, asansör, merdivenler, oturma alanları, saksılar...) olduğunu, 68 öğretmen adayının bu eşyaların sınıf içerisindeki eşyalar (akıllı tahta, sıralar...) olduğunu belirttikleri görülmektedir.

Tablo 6. Katılımcıların sınıfların fiziksel özelliklerinden memnun olma durumlarına göre dağılımı

\begin{tabular}{lll}
\hline Sinıfların fiziksel özelliklerinden memnun olma durumu & $\mathrm{f}$ & $\%$ \\
\hline Memnun değilim & 102 & 72.34 \\
Memnunum & 32 & 22.70 \\
Bilmiyorum & 6 & 4.26 \\
\hline Toplam & 141 & 100 \\
\hline
\end{tabular}

Bir sonraki bulguda katılımcıların sınıfların fiziksel özelliklerinden memnun olma durumları ele alınmış, bulgular tablo 6'da verilmiştir. Tablo 6'ya göre öğretmen adaylarının 102 tanesi sınıfların fiziksel özelliklerinden memnun olmadığını belirtmiştir. Bunun yanında 32 öğretmen adayının ise sınıfların fiziksel özelliklerinden memnun oldukları görülmüş̧ür. Sınıfların fiziksel durumundan memnun olmayan öğretmen adaylarından bazılarının görüşleri şu şekildedir;

k.5: Memnun değiliz bina yeni olmasına rağmen sinıflar dar ve küçük havalandırma yönünden de kalabalık olduğu için sinfflar yetersi

k.8: Sinıflarda bulunan siralar ahşap nitelikli olup oldukça rahatsızdır. Kürsü ve tahta herkesin görebileceği amfi tarzında değildir, binalar arası çok bitişik olduğu için derslerde başka bir sinıfla, özellikle yaz aylarında camlar açıkken, seslerimiz karışarak dikkat dağıtmaktadır. 
k.10: Hiç memnun değilim. Çok küçük. Ön sıralar tahtanın tam önüne denk geliyor. Istediğimiz gibi ögretim yöntemlerini yapamıyoruz. Sıralar çok rahatsız edici. Saatlerce oturmak bel fitı̆̆ garantili. Camlar çok büyük olduğu için açmak ayrı bir dert.

k.30: Sinıflar oldukça küçük ve mevcudumuz 43 kişi olduğundan sinıflara sığmada oldukça sıkıntı çektik. (Ayrıca bazı dersleri alttan alan öğrenciler de olduğunda sınıflar oldukça kalabalık ve havasız olmaktaydı.)

Araştırmada katılımcıların EF'nin amblemini bilip bilmedikleri de sorulmuş, bulgular tablo 7'de verilmiştir. Öğretmen adaylarına "eğitim fakültesinin ambleminin ne olduğu” sorulduğunda, katılımcıların 51 tanesinin amblemi eğitim ile ilişkilendirdiği, 49 tanesinin bilmediğini belirttiği, 45 öğretmen adayının Çanakkale ile ilişkili bir amblem olduğunu söylediği ve 10 öğretmen adayının ise bulundukları üniversite ile ilişkilendirdiği Tablo 7'de görülmektedir.

Tablo 7. Katılımcıların EF’nin amblemini bilme durumlarına göre dağılımı

\begin{tabular}{lll}
\hline EF’nin amblemini bilme durumu & $\mathrm{f}$ & $\%$ \\
\hline Eğitim ile ilişkilidir & 51 & 36.17 \\
Bilmiyorum & 49 & 34.75 \\
Çanakkale ile ilişkilidir & 45 & 31.91 \\
Diğer & 10 & 7.09 \\
Üniversite (ÇOMÜ) ile ilişkilidir & 10 & 7.09 \\
\hline Toplam & 141 & 100 \\
\hline
\end{tabular}

Diğer kategorisine yönelik görüş belirten katılımcıların bazılarının görüşleri şu şekildedir:

k.79: Mavi zemin üzerine yerleştirilmiş beyaz çizgiler üzerine yapılmış turuncu model

\section{k.43: Türkçe Ve Sosyal Bilimler Ĕ̈itimi}

k.58: Ödev kapaklarına eklediğimiz mavi bordo renkli şekil.

Tablo 8. Katılımcıların EF’nin logosunu bilme durumlarına göre dağılımı

\begin{tabular}{lll}
\hline EF'nin logosunu bilme durumu & $\mathrm{f}$ & $\%$ \\
\hline Bilmiyorum & 58 & 41.13 \\
Çanakkale ile ilişkilidir & 38 & 26.95 \\
Eğitim ile ilişkilidir & 31 & 21.99 \\
Üniversite (ÇOMÜ) ile ilişkilidir & 25 & 17.73 \\
Diğer & 11 & 7.80 \\
\hline Toplam & 141 & 100 \\
\hline
\end{tabular}

Öğretmen adaylarına "eğitim fakültesinin logosunun ne olduğu” sorulduğunda, katılımcıların çoğunluğunun \%41.13 oranında (f:58) logoyu bilmediğini belirttiği, 38tanesinin logoyu Çanakkale ile ilişkilendirdiği, 31 öğretmen adayının eğitim ile ilişkili bir logo olduğunu söylediği ve 25 öğretmen adayının ise logoyu bulundukları üniversite ile ilişkilendirdiği Tablo 8'de görülmektedir.

Tablo 9. Katılımcıların öğretim elamanlarının cüppelerinin rengini bilme durumlarına göre dağılımı

\begin{tabular}{lll}
\hline Öğretim üyelerinin cüppelerinin rengi & $\mathrm{f}$ & $\%$ \\
\hline Biliyorum & 75 & 53.19 \\
Bilmiyorum & 66 & 46.80 \\
\hline Toplam & 141 & 100 \\
\hline
\end{tabular}

Araştırma kapsamında ele alınan diğer bir bulgu katılımcıların öğretim elemanlarının cüppelerinin rengini bilip bilmediklerine ilişkindir. Tablo 9' da katılımcıların öğretim elemanlarının cüppelerinin rengini bilip bilmediklerine ilişkin görüşleri yer almaktadır. Tablo 9 incelendiğinde görüş belirten 141 katılımcının 75 tanesinin öğretim elemanlarının cüppelerinin rengini bildiği, 66 katılımcının ise bilmediğini belirttiği görülmüştür. Tablo 10'da ve tablo 11 'de sırası ile katılımcıların EF'nin misyonunu ve vizyon bilme durumları ele alınmıştır.

Tablo 10. Katılımcıların EF’nin misyonunu bilme durumlarına göre dağılımı

\begin{tabular}{lll}
\hline EF'nin misyonunu bilme durumu & f & $\mathbf{\%}$ \\
\hline Öğretmen yetiştirmek & 54 & 38.30 \\
Nitelikli bir fakülte olmak & 48 & 34.04 \\
Bilmiyorum & 43 & 30.50 \\
\hline Toplam & 141 & 100 \\
\hline
\end{tabular}


Tablo 10'a göre öğretmen adaylarının 54'ünün eğitim fakültesinin misyonunu öğretmen yetiştirme ile ilişkilendiği, 48 öğretmen adayının ise nitelikli bir fakülte olmak ile ilişkili olduğunu belirttiği görülmektedir. 43 öğretmen adayı ise EF'nin misyonunu bilmediklerini ifade etmişlerdir.

Tablo 11. Katılımcıların EF’nin vizyonunu bilme durumlarına göre dağılımı

\begin{tabular}{lll}
\hline EF'nin vizyonunu bilme durumu & f & \% \\
\hline Öğretmen yetiştirmek & 63 & 44.68 \\
Bilmiyorum & 45 & 31.91 \\
Nitelikli bir fakülte olmak & 38 & 26.95 \\
\hline Toplam & 141 & 100 \\
\hline
\end{tabular}

Tablo 11 incelendiğinde katılımcıların 63 tanesinin eğitim fakültesinin vizyonunu öğretmen yetiştirme ile ilişkilendiği, 45 öğretmen adayının ise nitelikli bir fakülte olmak ile ilişkili olduğunu belirttiği görülmektedir. 38 öğretmen adayı ise eğitim fakültesinin vizyonunu bilmediğini söylediği görülmektedir.

Şekil 2. Kod birlikte oluşturma modeli çakışan kodlar: katılımcıların EF’nin vizyonunu bilme durumlarına göre dağılımı

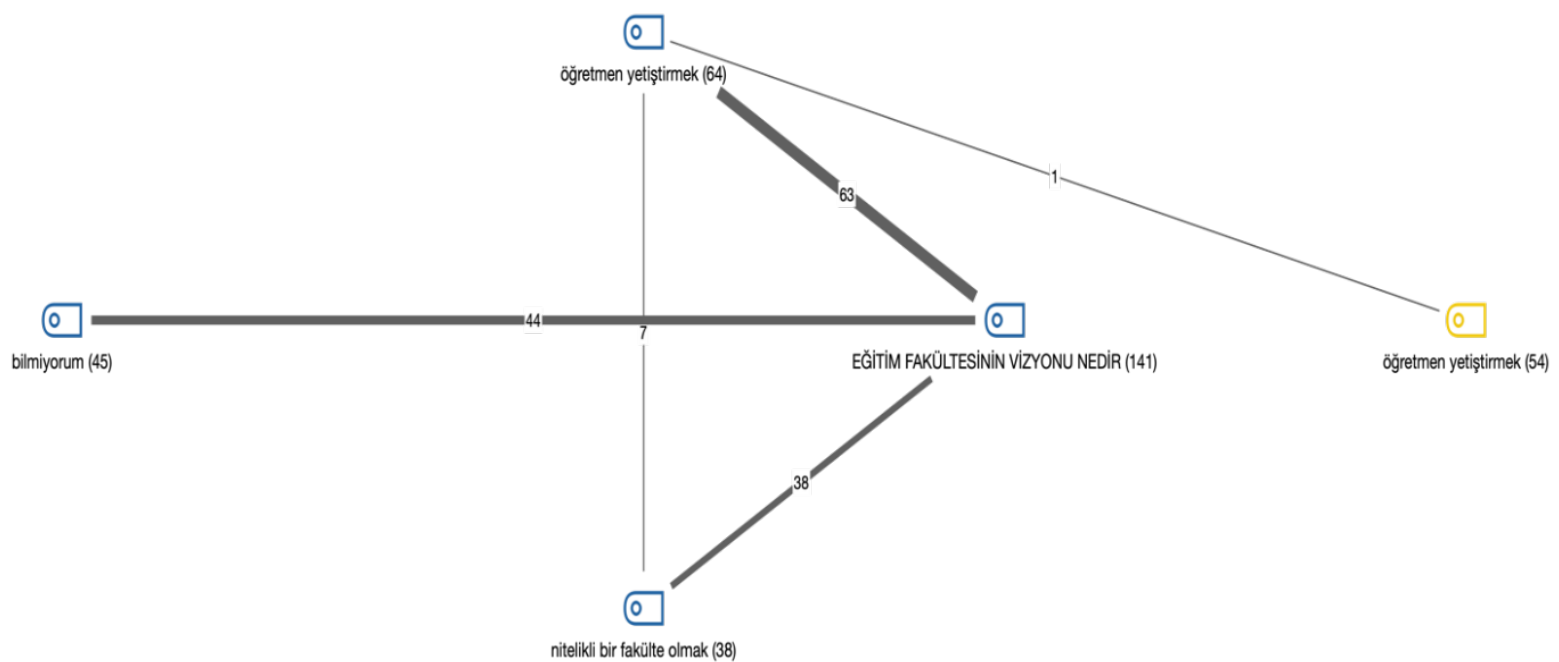

Şekil 2'ye göre EF'nin vizyonunu bildiğini belirten öğretmen adaylarının 64 tanesi vizyonu öğretmen yetiştirmeyle ilişkilendirmiştir. Bu 64 öğretmen adayından 7'sinin aynı zamanda vizyonu nitelikli bir fakülte olmayla da ilişkilendirdiği tespit edilmektedir. Aynı şekilde öğretmen yetiştirme ile ilişkilendiren 64 katılıcının 54 tanesinin “EF’nin misyonunu biliyor musunuz?" sorusuna verdikleri cevaplarını öğretmen yetiştirme ile ilişkilendirdikleri (sarı etiketli şekil) şekil 1'de görülmektedir. Katılımcılara EF’nin misyon ve vizyonunun nerde yazıldığı sorulmuş, bulgular tablo 12'de gösterilmiştir.

Tablo 12. Katılımcıların EF’nin vizyonu ve misyonun nerede yazdığını bilme durumlarına göre dağılımı

\begin{tabular}{lcc}
\hline Vizyonu ve misyonun nerede yazdığını bilme durumu & $\mathrm{f}$ & $\%$ \\
\hline Okulun internet sitesinde & 66 & 46.81 \\
Bilmiyorum & 57 & 40.43 \\
Fakülte içerisinde & 12 & 8.51 \\
\hline Toplam & 141 & 100 \\
\hline
\end{tabular}

Katılımcıların EF'nin misyonunun ve vizyonunun nerede yazdığını bilme durumlarına bakıldığında katılımcıların \%46.81'e denk gelen çoğunluğunun (f:66) okulun internet sitesinde yazdığını belirttikleri görülmektedir. 57 katılımcının ise bilmediğini belirttiği ve 12 öğretmen adayının ise fakülte içerisinde bir yerde yazdığını söylediği Tablo 12'de görülmektedir.

Bir diğer bulgu katılımcıların EF'nin internet sitesini kullanma sıklığg ile ilgilidir. Tablo 13'de gösterilmiştir. Tablo 13 incelendiğinde, 62 öğretmen adayının eğitim fakültesinin internet sitesini duyurular için kullandığını belirttiği, 45'inin çok az kullandığını, 30 öğretmen adayının ödevler ve ders notları için kullandığını, 18'inin akademik takvim için kullandığını, 17'sinin kullanmadığını ve 5 katılımcının da UBYS için kullandığını belirttikleri görülmektedir. 
Tablo 13. Katılımcıların EF’nin internet sitesini kullanma sıklıklarına göre dağılımı

\begin{tabular}{lll}
\hline EF'nin internet sitesini kullanma sıklıkları & f & \% \\
\hline Duyurular için kullanıorum & 62 & 43.97 \\
Çok az kullanıyorum & 45 & 31.91 \\
Ödevler ve ders notları ve sınavlar için kullanıyorum & 30 & 21.28 \\
Akademik takvim için kullanıyorum & 18 & 12.77 \\
Kullanmiyorum & 17 & 12.06 \\
UBYS için kullanıorum & 5 & 3.55 \\
\hline Toplam & 141 & 100 \\
\hline
\end{tabular}

Şekil 3. Kod birlikte oluşturma modeli çakışan kodlar: katılımcıların ef’nin internet sitesini kullanma sıklıklarına göre dağılımı

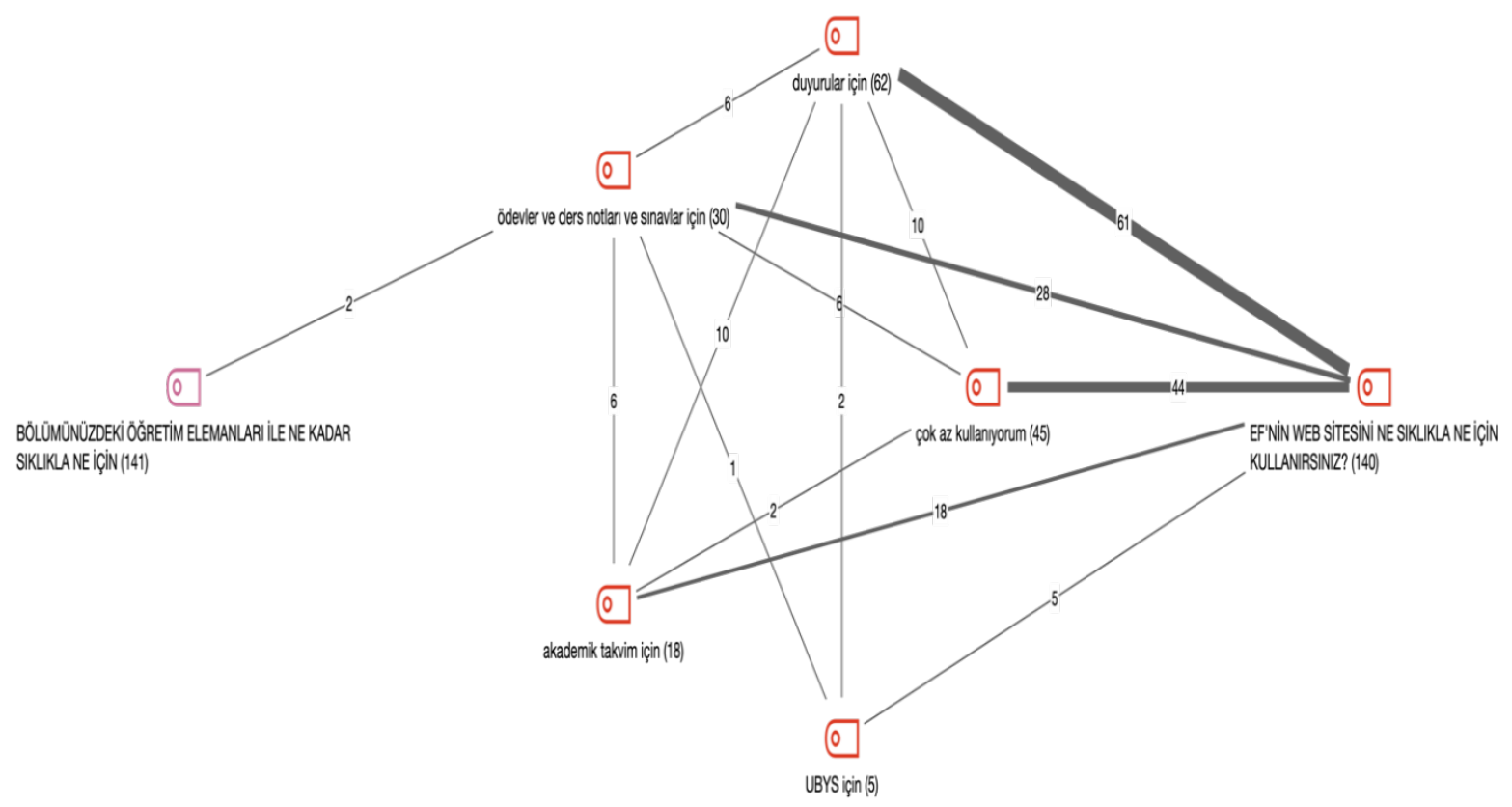

Kod birlikte oluşturma modeli incelendiğinde, eğitim fakültesini duyurular için kullandığını belirten 62 öğretmen adayının 10 tanesinin siteyi aynı zamanda çok az kullandığı, 6 tanesinin ödevler ve dersler içinde kullandığını ve 10 tanesinin de akademik takvim için de kullandığını belirttiği görülmektedir. Eğitim fakültesi internet sitesini çok az kullandığını belirten 45 katılımcının 6 tanesi siteyi ödev ve ders notları için,2 tanesi akademik takvim için kullandığını belirtmiştir.

Tablo 14. Katılımcıların öğretim elemanlarıyla iletişime geçme sıklıklarına göre dağılımı

\begin{tabular}{lll}
\hline Öğretim elemanlarıyla iletişime geçme sıklıkları & $\mathrm{f}$ & $\%$ \\
\hline Yalnızca ödevler ve ders konusunda iletişim kuruyorum & 81 & 57.45 \\
Çok az iletişim kuruyorum & 45 & 31.91 \\
Sıklıkla iletişim kuruyorum & 24 & 17.02 \\
\hline Toplam & 141 & 100 \\
\hline
\end{tabular}

Tablo 14 incelendiğinde, 81 öğretmen adayının öğretim elemanlarıyla yalnızca ders ve ödevler konusunda iletişim kurduğunu belirttiği, 45'inin çok az iletişim kurduğu, 24 öğretmen adayının ise sıklıkla iletişim kurduğu görülmektedir.

Tablo 15. Katılımcıların öğretim elemanlarıyla iletişime geçme şekillerine göre dağılımı

\begin{tabular}{lll}
\hline Öğretim elemanlarıyla iletişime geçme şekilleri & $\mathrm{f}$ & $\%$ \\
\hline Mail & 103 & 73.05 \\
Whatsapp & 80 & 56.74 \\
Yüz yüze görüşme & 45 & 31.91 \\
Diğer & 19 & 13.48 \\
Telefon ile sesli arama & 11 & 7.80 \\
\hline Toplam & 141 & 100 \\
\hline
\end{tabular}

Copyright (C) 2021 by IJSSER

ISSN: 2149-5939 
Katılımcıların bulundukları fakültede öğretim elemanlarıyla iletişime geçme şekillerine bakıldığında Tablo 15'ye göre çoğunluğun (f:103) Mail ile iletişim kurduğu, 80 katılımcının Whatsapp ile, 45 tanesinin yüz yüze görüşme ile ve 11 öğretmen adayının ise telefon ile sesli arama şeklinde iletişime geçtikleri tespit ediliştir. 19 öğretmen adayı ise diğer (SMS, Teams, Instagram...) kategorisine yönelik görüş belirtmiştir.

Şekil 4. Kod birlikte oluşturma modeli çakışan kodlar: katılımcıların öğretim elemanlarıyla iletişime geçme şekillerine göre dağılımı

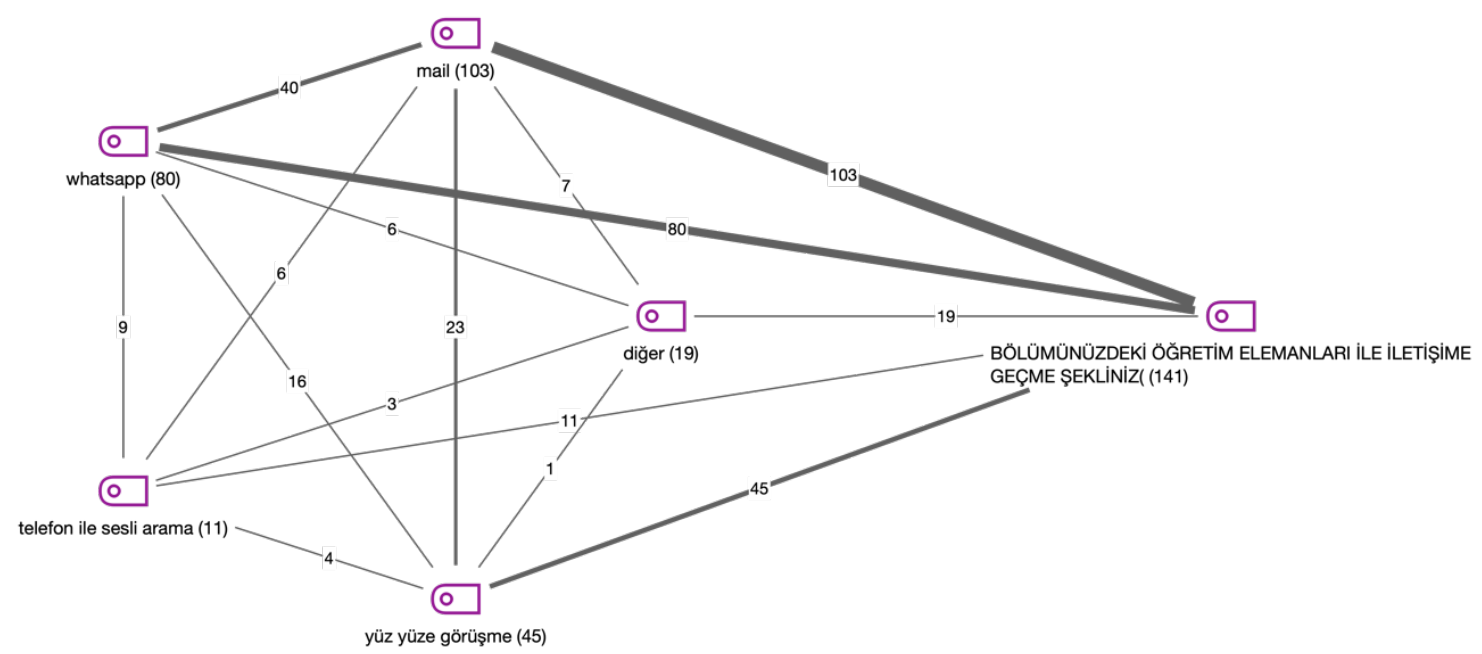

Öğretim elemanlarıyla mail ile iletişime geçtiğini belirten 103 öğretmen adayının 40 tanesinin aynı zamanda whatsapp, 23 tanesinin yüz yüze görüşme, 6'sının telefon ile sesli arama yolu ile de iletişime geçtiği Şekil 4'de görülmektedir.

Araştırma kapsamında katılımcılara fakültede en hayran oldukları kişi sorulmuştur. Alınan cevaplarda kişi ismi verilmemiş öğretim elemanı şeklinde bulgulaştırılmıştır. Görüşler tablo 16'da verilmiştir.

Tablo 16. Katılımcıların EF’de hayran oldukları kişi

\begin{tabular}{lll}
\hline Katılımcıların EF'de hayran oldukları kişi & $\mathrm{f}$ & $\%$ \\
\hline Öğretim elemanı & 112 & 79.43 \\
Yok & 19 & 13.48 \\
Memur & 1 & .71 \\
Diğer & 1 & .71 \\
Yönetici & 1 & .71 \\
\hline Toplam & 141 & 100 \\
\hline
\end{tabular}

Tablo 16 incelendiğinde, 112 öğretmen adayının eğitim fakültesinin hayran olduğu en az bir kişi olduğunu belirttiği, 19 tanesinin böyle bir kişi olmadığını, 1 öğretmen adayının ise bir memura hayran olduklarını ifade ettikleri görülmektedir. Eğitim fakültesinde hayran oldukları kişinin öğretim elemanı olduğunu belirten öğretmen adaylarından çoğunluğu yalnızca isim ya da isimler yazsa da bazılarının görüşleri şu şekildedir;

k.21: ...... hocayla ...... hocayı kendi hemcinsim olduğu için ve duruş anlamında kendime rol model alıyorum ...... hocayla bazı fikirlerimiz hayata bakış açımız benziyor öte yandan ...... hocada öğrencilerine karşı tutumu davranışı benim çok hoşuma gidiyor ayrıca hem annelik hem de akademisyenlik anlamında bence çok başarılı ilerde onun gibi olmak isterim

k.64: öğrencilere karşı ilgi ve tutum bakımından ...... Ders işleme, anlatma ve bizleri yönlendirme bakımından ..... Bizleri yönlendirmesi ve okul öncesi öğretmenliğinde bizlere uygulama firsatı sunması açısından ....... Derslerinde hayat ile ilgili gerçekleri yansitması ve öğrenci psikolojisini son derece düşünerek ders işleyen, bizlerle iletişim kurarken değer verdiğin hissettiren hocam .......

k.109: Biyoloji adına yüksek lisans istiyorum bu yüzden ....... ve ...... hocalarımı takip ediyorum. Ayrıca genel olarak farklı çalışmalar yapan tüm hocalarıma da hayranım denebilir.

\section{k:113: Hocalarin hepisine}

k.131: hoca, tarzına ve kişiliğine hayranım, cesur ve bakış açısı beni aşırı derecede etkiliyor. Not konusunda aşırı adil ve ögrencilerin fikirlerine önem veriyor 
Tablo 17'de katılımcıların EF'de rol model aldıkları ve onları motive eden kişilere ilişkin bulguları verilmiştir.

Tablo 17. Katılımcıların EF'de rol model aldıkları ve onları motive eden kişi

\begin{tabular}{lll}
\hline Katılımcıların EF'de rol model aldıkları ve onları motive eden kişi & f & $\%$ \\
\hline Öğretim elemanı & 105 & 74,47 \\
Yok & 23 & 16,31 \\
Diğer & 6 & 4,26 \\
\hline Toplam & 141 & 100 \\
\hline
\end{tabular}

Tablo 17'ye göre, 105 katılımcının eğitim fakültesinde kendine rol model olarak gördüğü ve kendilerini motive ettiğini söyledikleri kişi ve/veya kişilerin öğretim elemanlarının arasından olduğunu belirttiği, 23 tanesinin böyle bir kişi olmadığını, 6 öğretmen adayının ise diğer kategorisine yönelik (annem, Hz. Muhammed, ilkokul öğretmenim...) belirttikleri görülmektedir. Eğitim fakültesinde onları motive eden kişinin öğretim elemanı olduğunu belirten öğretmen adaylarından çoğunluğu yalnızca isim ya da isimler yazsa da bazılarının görüşleri şu şekildedir;

k.93: ....... hocamın çok güzel motive cümleleri var ders işlerken hayatımızın içinden olayları derse katması bende dersin daha kalıcı olmasına yardımcı oluyor. Ders esnasında sorular sorarak aktif olarak katılmamızı sağlıyor ve beni bu şekilde motive ediyor. Yüz yüze eğitimde ders işlerken ara ara kişilik envanter çalışmaları ve bunlara yönelik ödevler vermesi beni motive ediyor ve kendimi, kendime karşı ifade etmeme yardımcı oluyor.

k.11: ....... kimya hocam. Gerçekçi konuşmaları olduğu için gelecekle ilgili karar vermemde mantıklı düşünmemi sağllyor ve beni motive ediyor.

k.116: Derslerime giren bütün hocalarım bu sorunun cevabıdır. Çünkü akademisyenlik hayalimde her ders gördüğ̈̈m hocalarım benim için motive kaynă̆ı olmuştur.

k.129: ...... öğrencilerin dilinden anlayan, 0 ego sahibi, güler yüzlü ve dünyanın en anlayışlı insanı, akademik olarak tam doyuruculuk sağlayan biri.

k.137: ....... çünkü bakış açısı ve ders dışındaki güncel bilgileri beni çok etkiliyor ve hayranlık duyup motive oluyorum. Ayrica not konusunda adaletli.

Katılımcıların araştırma kapsamında kendilerini motive eden olayın ne olduğuna ilişkin görüşleri de alınmış, görüşleri tablo 18 'de verişmiştir.

Tablo 18. Katılımcıların motive eden olay

\begin{tabular}{lll}
\hline Katılımcıları en iyi motive eden olay & f & $\%$ \\
\hline Yok & 41 & 29.08 \\
Başarı/sınav notları & 31 & 21.99 \\
Hocaların desteği ve tutumu & 25 & 17.73 \\
Diğer & 23 & 16.31 \\
Öğretmenlik mesleği & 15 & 10.64 \\
Bu okulda bulunmak & 3 & 2.13 \\
\hline Toplam & 141 & 100 \\
\hline
\end{tabular}

Tablo 18 incelendiğinde, 41 öğretmen adayının kendilerini motive bir olayın bulunmadığını belirttiği, 31 katılımcının, başarı ve sınav notlarını, 25 tanesinin hocaların desteğini, 15 tanesinin öğretmenlik mesleğin ve 3 tanesinin ise bu okulda bulunmanın kendilerini motive eden olay olarak belirttikleri görülmektedir. Hocaların desteği ve tutumuna ilişkin olarak görüş belirten katılımcılardan bazılarının görüşleri şu şekildedir;

k.10: ......... ’nın 1. sınıfta dediği; günümüz kahramanlarl sokaktan değil kütüphaneden çıkacak sözü. Ne zaman ders çalışmak istemesem aklıma bu sözü gelir.

\section{k.20: Yüksek enerjili ögretmenlerin güdüleyici ve yaptığımız işe değer verdiğini hissettiren konuşmaları}

k.37: Hocaların bize hocam diye hitap etmesi

k.40: Ö̆̆grenciye hakkını hak ettiği şekilde ne az ne çok veren, özel bir muamele yapılmadan değerlendirmelerin yapılmast

k.66: Hocalarımızın derslerde imkansız gibi görünen ama uzun uğraş sonucu ulaştıkları başarıları anlattıkları olaylar. 
k.112: Biyoloji ve anatomi dersinde sınıfa girdiğimde bana günaydın pınar demesi ismimi bilmesi ve bir şeyi doğru yaptı̆̆ımda övmesi beni motive ediyordu.

k.117: Öğretmenlerimin sabırll yaklaşımları. Tek bir olay gelmiyor aklima. Yakın zamanda çok ciddi üç operasyon geçirdim. Tüm o sağllk sıkıntılarıma rağmen derslere katıldım, çalıştım, çabaladım. Benim motivasyonum içten geliyor. Yaş itibariyle genelin üzerindeyim, Hayata karşı sorumluluklarım var ve gerçekten hayalim olan bölümü okuyorum. Açıkçası ekstra motivasyona ihtiyaç duymuyorum. Anlamaya çabaladı̆̆ım zamanlarda öğretmenlerimin davranışları ile bu motivasyon hiç düşmüyor. Ĕger aksi bir tavırla yaklaşsalardı sanırım bu durum beni etkilerdi.

k.138: Bir hocamızın birkaç arkadaşımızla bizi Çanakkale' deki bir köy okuluna götürüp öğrencilerle ders işlememizi sağlamast.

Öğretmenlik mesleğinin motive etmesine ilişkin olarak görüş belirten katılımcılardan bazılarının görüşleri şu şekildedir;

\section{k.3: Bir gün ögrrencilerimle ders işleyebilecek olmak}

k.7: Hayalimdeki mesleği yaparak yeni nesillerin, Türk Milleti için faydalı bireyler olmasına katkl sağlayabilecek olma düşüncesi

k.23: Okul derslerimi yüksek notla geçmek ve ögretmenlik hakkında her gün yeni deneyimler kazanmak beni motive eder.

k.34: Öğretmenliğin ne kadar önem arz ettiğini, hocalardan ve toplumdan duymak.

k.60: Okul gözlemine gittiğimde çocukların "Elif Öğretmenim" şeklinde hitap etmeleri beni çok motive etmişti

k.99: Küçük çocukların bir şeyler öğrenebilmek için gözümün içine bakttğı o dönemde onlara ögrretebildiğim ne varsa ögretmeyi hayal ediyorum. Onlara layık olmak için çalışmak beni motive ediyor. Bazen ders çalışırken slkılsam bile bunu onlar için yaptığım aklıma geliyor ve daha istekli oluyorum.

\section{k.110: Öğretmenlik Aşkı}

Katılımcılara ayrıca öğrencilik hayatlarında hafizlarına kazınan bir olay olup olmadığı da sorulmuş, bulgular tablo 19 'da verişmiştir.

Tablo 19. Katılımcıların hafizalarına kazınan olay

\begin{tabular}{lll}
\hline Katılımcıların hafizasına kazınan olay & $\mathrm{f}$ & $\%$ \\
\hline Yok & 65 & 46.10 \\
Diğer & 17 & 12.06 \\
Hocaların davranışları & 14 & 9.93 \\
Ders sırasında gerçekleşen olaylar & 11 & 7.80 \\
Ders sunumları & 8 & 5.67 \\
Sinav çalışmaları & 8 & 5.67 \\
Okulun ilk günü & 6 & 4.26 \\
Okulun yıkılması & 5 & 3.55 \\
Okuldaki faaliyetler & 4 & 2.84 \\
Pandemi & 3 & 2.13 \\
\hline Toplam & 141 & 100 \\
\hline
\end{tabular}

Tablo 19'a göre katılımcıların büyük oranda (f:65) hafizalarına kazınan bir olaya ilişkin görüş belirtmedikleri görülmüştür. 14 katılımcının hocaların davranışlarının, 11'inin ders sırasında gerçekleşen olayların, 8 tanesinin ders sunumlarının, 8 tanesinin sınav çalışmalarının, 6 katılımcının okulun ilk gününün, 5 katılımcının eğitim fakültesinin yıkılıp yeniden yapılmasının ve 3 tanesinin ise pandemi sürecinin hafızalarına kazınan olay olduğunu söylediği tespit edilmiştir. Hocaların davranışlarının hafızalarına kazınan bir olay olmasına ilişkin olarak görüş belirten katılımcılardan bazılarının görüşleri şu şekildedir;

k.21: Cok var ama ...... hocanın bir hatamı gördü̈̆̈̈nde kendine gel demesi benim için bazen çok yeterli oluyor bir kerede final sınavinda çok saçma bir soruyu yanlış yaptığımı görünce .... hoca koridorda kenara çekip sen nasll cevap veriyorsun öyle O soruyu nasıl yanlış yaparsın demesiyle sinavlarda daha dikkatli davranmıştım

k.26: Öğretim görevlilerinin arasında kavgalar olabilir, davalar vs

k.111: Bir gün bir hocam sürekli derslerde uyuduğumu ama yine de dersten geçtiğime şaşırdlğını söylemişti. Çalışmadı̆̆ın için önüme çıkan firsatları kaçırma ihtimalimi hatırlatıp beni motive etmişsti 
k.117: Bir öğretmenimizin durduk yere koridorda bă̆ırması daha doğrusu haklı olmasına rağmen aşırı ve rencide edici şekilde bă̆ırmast.

k.140: Şehit polis Nefize Özsoy'un fakültemiz mezunu ....... hocamızın da öğrencisi olmasl ve ona polis olacağını bildirmesi hocamızın ise onun öğretmen olmasını istemesidir.

k.105: ..........'ın bir dersinde yaptı̆̆ım sunum ve bana söyledikleri. Kibritçi Kız canlandırması yapmıştım. Öğretmen olsam ya da olunca bu şekilde yapardım dediğimde benim zaten böyle düşünmekle ve yapmakla artık gerçek bir ögretmen olduğumu söylemişti.

k.42: Ben Türk Dili ve Edebiyatı mezunuyum ve bu 2.üniversitem. Türkçe Eğitimi bölümünü kazandım ve başladı̆̆ım ilk zamanlardı. Uzem için ders şifrelerini almaya bir asistan vs birisinin odasına gittiğimde bölümde olan fakat anladı̆̆ım kadarıyla seçmeli derslere giren bir hoca da vardı. Durumumu öğrendiklerinde Ikisi beraber üstüme yüklenmişlerdi ve hoca bu bölümü okumamın vakit kaybı olduğunu söylemişti, beni kpss edebiyata çalışmamakla suçlamıştı ve bundan hariç küçük düşürücü sözlerde bulunmuştu. Ayrıca kendi bölümümüzdeki öğrencilerin haberi yok ama (Türkçe Öğrt.kastediyor) bu bölümün önü de yakın zamanda tıkanacak ve atanamayacaklar vs demişti. Bir hocanın, kendi bölümü ve ögrencileri için böyle düşüncelere sahip olması beni çok üzdü. Bu üniversiteye ve fakülteye olan olumlu tutumumu bir nebze değiştirdi diyebilirim. Üstelik ben bu üniversiteye ve bu eğitim fakültesine güzel hayallerle gelmişken. Başta dediğim gibi eğitim fakültesi hocalarının hepsi insaniyetli sanırdım fakat bunun eğitimle ilgili olmadı̆̆ını anladım. Yaşadıklarım başarılı olmak için beni ne kadar üzse de hırslandırdl. Üstten bir sürü ders aldım ve en kısa zamanda okulumu bitiricem inşallah.

Tablo 20. Katılımcıların EF ile ilgili duyduğun hikayeler

\begin{tabular}{lll}
\hline Katılımcıların EF ile ilgili duyduğun hikayeler & $\mathrm{f}$ & $\%$ \\
\hline Yok & 109 & 77.30 \\
Var & 32 & 22.69 \\
\hline Toplam & 141 & 100 \\
\hline
\end{tabular}

Katılımcıların EF ile ilgili duyduğu hikayelere ilişkin görüşleri tablo 20'de verilmiştir. Tablo 20 incelendiğinde görüş belirten 141 katılımcının 109 tanesinin eğitim fakültesine özel anlatılan bir hikaye veya efsane olmadığını, 32 katılımcının ise böyle bir hikaye olduğunu belirttiği tespit edilmiştir. Bir efsane duyduğunu belirten öğretmenlerin görüşlerinden bazıları şu şekildedir;

k.8: O kadar çok efsane, hikaye, olay duyuyoruz ki. Ama bunlar yaşanması muhtemel ya da yaşanmamış, asparagas olma ihtimali olan olaylar olacağı için anlatmanın etik olduğunu düşünmüyorum.

k.58: ben tesettürlü bir ögrrenciyim. Üniversite ye başladığımda bölümden bir kaç ögrenci bana bazı hocaların tesettürlü öğrencilere kötü davrandı̆̆ını dışlandığımı hatta dersten biraktı̆̆ını anlattı. Bende haliyle bunlara inanıp korkmuştum hatta bu durumdan dolayı daha başında okulu bırakmayı düşündüm ailem izin vermedi ve psikolojik destek aldım. Danışmanım bana 'başarıyı hiçbir şey örtemez gölgeleyemez' demişti. Fakültede ki hocalarla o ögrencilerin bahsettiği olumsuz durumlardan hiçbirini yaşamadım. Hocaların ismini de söylemişlerdi. O bahsettikleri hocaları o kadar sevdim ki. Onlarda beni seviyor inanıyorum kalpten. Bu olay bana kendi tecrübelerimle hareket etmeyi başka insanların tecrübeleriyle, algllarıla anlattı̆̆ şeyleri değerlendirmeyi ama asla olduğu gibi kabul etmeyi ögretti.

k.73: Dördüncü kata merdiven yapmayı unutmaları çok tuhaftı duyunca şaka zannetmiştim k.76: Hem fakülte hem öğretmenlik anlamında bakarsam ĕger kolay bölüm zaten, eğleniyorsunuz vs. Deniliyordu. Ĕ̆lendim ama kendimi sürece dahil ettiğim için ĕglendim. Emek verdiğim için eğlendim diye düşünüyorum ve düşünülenin aksine çok kolay ya da çok zor olduğunu düşünmüyorum.

k.109: ... domuz girmiş dediler.

k.130: Fakültenin eski binasının çok daha iyi olduğunu duydum genelde

k.96: ç3 efsaneleri, fakültenin eski binasının öğretmen lisesi olduğu, başka yok.

Tablo 21. EF'de kullanılan özel bir özel bir dil

\begin{tabular}{lll}
\hline EF kullanılan özel bir dil & $\mathrm{f}$ & $\%$ \\
\hline Yok & 128 & 90.78 \\
Var & 13 & 9.21 \\
\hline Toplam & 141 & 100 \\
\hline
\end{tabular}


Araştırmada ayrıca katılımcılara EF'de kullanılan özel bir dil olup olmadığı da sorulmuş, bulgular tablo 21 'de verilmiştir. Tablo 21 'e göre görüş belirten 141 katılımcıların 128 tanesinin eğitim fakültesine özel anlatılan bir dil olmadığını, 13 katılımcının ise böyle özel bir dil olduğunu belirttiği görülmektedir.

Tablo 22'de katılımcıların EF'de katıldıkları etkinliklere ilişkin görüşleri verilmiştir.

Tablo 22. Katılımcıların katıldığı etkinliklerin ne olduğuna ilişkin dağılımı

\begin{tabular}{lcc}
\hline Katılımcıların katıldı̆̆1 etkinliklerin ne olduğuna ilişkin dağılım & $\mathrm{f}$ & $\%$ \\
\hline Katılmadım & 53 & 37.59 \\
Seminer/Konferans/Sempozyum & 33 & 23.40 \\
Öğrenci toplulukları & 26 & 18.44 \\
Diğer & 19 & 13.48 \\
Geziler & 19 & 13.48 \\
Bahar Şenlikleri & 7 & 4.96 \\
Oryantasyon & 3 & 2.13 \\
\hline Toplam & 141 & 100 \\
\hline
\end{tabular}

Tablo 22 incelendiğinde katılımcılardan çoğunluğunun (f:53) eğitim fakültesinde herhangi bir etkinliğe katılmadığı görülmektedir. Katılımcıların 33 tanesi Seminer/Konferans/Sempozyum gibi etkinliklere, 26 tanesi öğrenci topluluklarının etkinliklerine, 19 tanesi gezilere, 7 tanesi bahar şenliğine ve 3 tanesi ise oryantasyona katıldığını belirtmiştir.

Araştırma kapsamında ele alınan diğer bir bulgu katılımcıların EF'de hoşnutsuzluk duydukları durum ile ilgilidir. Tablo 23'de gösterilmiştir.

Tablo 23. Katılımcıların EF'de hoşnutsuzluk duyduğu durum

\begin{tabular}{lll}
\hline Katılımcıların EF'de hoşnutsuzluk duyduğu durum & $\mathrm{f}$ & $\%$ \\
\hline Fiziki yapı & 60 & 42.55 \\
Eğitim & 28 & 19.86 \\
Yok & 25 & 17.73 \\
Diğer & 16 & 11.35 \\
Hocalar & 15 & 10.64 \\
İdari konular & 13 & 9.22 \\
Sosyal anlamda & 11 & 7.80 \\
\hline Toplam & 141 & 100 \\
\hline
\end{tabular}

Tablo 23 incelendiğinde katılımcılardan çoğunluğunun (f:53) eğitim fakültesinde fiziki yapıdan hoşnutsuz olduğu görülmektedir. Katılımcıların 28 tanesi eğitimden, 15 tanesinin hocalardan, 13 tanesinin idari konulardan, 11 'inin ise sosyal konulardan sızlandığı tespit edilmiştir. Öğretmen adayların sızlandığı/memnun olmadığı durum olarak fiziki yapıdan bahseden bazılarının görüşleri şu şekildedir:

\section{k.3: Sinıfların çok kü̧̧ük, koridorlarınsa çok büyük olması}

k.31: Yeterli araç gereç donanımına sahip olmamasl, derslerde yeterli bilgi ve becerilerin verilmemesi. (öğretmen olduğumuzda neler yapamamız gerektiğiyle ilgili). Derslerin daha çok sunum odakl geçmesi ve ögretim elemanlarınin bu sebeple yeterli bilgiyi aktaramamast.

k.38: Fakültenin fiziki durumundan hiç memnun değilim ama artık gidemediğimiz için bu problemi unuttum . Diğer yakındığım konu uzaktan eğitim döneminde hocaların anlaylı̧lı davranmamask. 104: Peyzajının kötü olması. Öğrencilerin şöyle çimlerde oturup ya da kamelyalarda oturup çayın kahvesini içeceği sohbet edebileceği bir alan yok.

k.114: Fakülte binasının en üst katına merdiven yok. Binanın çevresinde oturacak alan yok

k.127: Bina yetersizliği, tuvaletlerde kağıt olmaması.... Ama şu an buna bile razlyım. eden eğitim zor.... Özellikle enstrüman dersleri.

k.141: bulunduğu konum dolaylsıyla etrafindaki ev ve yurt fiyatları oldukça fazla. Kampüs içinde olmasinı tercih ederdim. Farklı bir yerleşke olduğundan dolayı bahçesinin öğrenciler için daha sosyal bir ortam sunmasını isterdim.

Öğretmen adayların sızlandığı/memnun olmadığı durum olarak idari konulardan bahseden bazılarının görüssleri şu şekildedir: 
k.74: Sınıfların bölünmesi, lisedeki gibi şube olması ders programını çok karlştırıyor. Alttan alınan dersler için her defasında bir sürü kişinin onayını almak ve kendi programıma uydurmak büyük enerji ve zaman kaybı. Okuldayken de ders onayları bittikten sonra sitedeki liste güncellenmiyordu. Derse girilen sinıfin, günün, saatin değişmesi sebebiyle kaçırdiğım dersler olmuştu.

\section{k.77: Öğrenci işleri/ Okul logolu ürünlerin satılmaması}

\section{k.92: Ubys deki teknik sıkıntılar Kayıt yenileme sorunları Seçmeli dersler}

k.93: Öğrenci işlerinde işlerin çok yavaş ilerlemesi ve bazı konularda bizi ertelemesi.

k. 135: Öğrenci işlerinin ilgili olmaması, işlerinin çok yavaş ilerlemesi, öğrenci işlerinden kaynaklı bir sorunun nedenini onların bulmasl gerekirken benim bulmak zorunda kalmam

Öğretmen adayların sızlandığı/memnun olmadığı durum olarak hocalardan bahseden bazılarının görüşleri şu şekildedir:

k. 1: Bazı ögretmenler hiç halden anlamıyor. Daha saygı çerçevesinde ilerleseydi mutlu olurdum.

k.8: Ders programlarının ve içeriğinin düzenlenmesinin çok işlevsel olduğunu düşünmüyorum. Bazı hocalarımızın da sınav ya da ödevlendirme yapmayacă̆ım diyerek final haftası içinde ödevlendirme yapıp iki gün süre vermesi de en çok şikayetçi olduğum konulardan birisi.

k.13: Yeterince donanımlı hocaların bulunmaması ve hocaların bizimle yeteri kadar ilgilenmemesi. Asıl amaç iyi birer insan yetiştirmek ezber yapan bir öğretmen değil umarım ben bunu başarırım

k.29: Bazı öğretmenlerin aşırı sorumsuz olması. Genelde öğretmenlerin akademik çalışmaları ögrencilerden daha önemli önemli. Bence, öğretmenlerin okulla ilgili öncelikleri, öğrencileri olmal, tabi bu benim görüşüm.

k.94: Hocalar uzaktan eğitim sürecinde çok fazla ödev vermekte. Ödevin niteliğinden çok niceliğine bakalıyor gibi geliyor. Çok ödev verildiği takdirde konuları daha iyi ögrenmiyoruz. Bilakis, aradan çıssın da diğer ödevleri yetiştirelim diye uğraşıyoruz. Ödev yükünün fazla olmasının verimli olduğunu düşünmüyorum. Ayrıca bazı derslerin ödevlerinde bölümümüz itibariyle materyal almak gerekiyor. Benim bir ders için 200-250 lira ayıracak bütçem olmasına rağmen maddi durumu iyi olmayan arkadaşlarımız bu konuda sıkıntı yaşamakta. Bazı hocalarımızın ödev verirken bunu da dikkate aldı̆̆ını düşünmüyorum. Ayrıca pandemi nedeniyle sokağa çıkma kısıtlamaları bulunmakta, malzeme alınabilecek dükkanlar da kapalı olunca mecbur internetten alış veriş yapmak zorunda kaldı̆̆ımız da oluyor. Kredi kartı kullanmayan ve internetten alış veriş yapmasını bilmeyen insanlar olduğunu da dikkate almak gere

Şekil 5. Kod birlikte oluşturma modeli çakışan kodlar

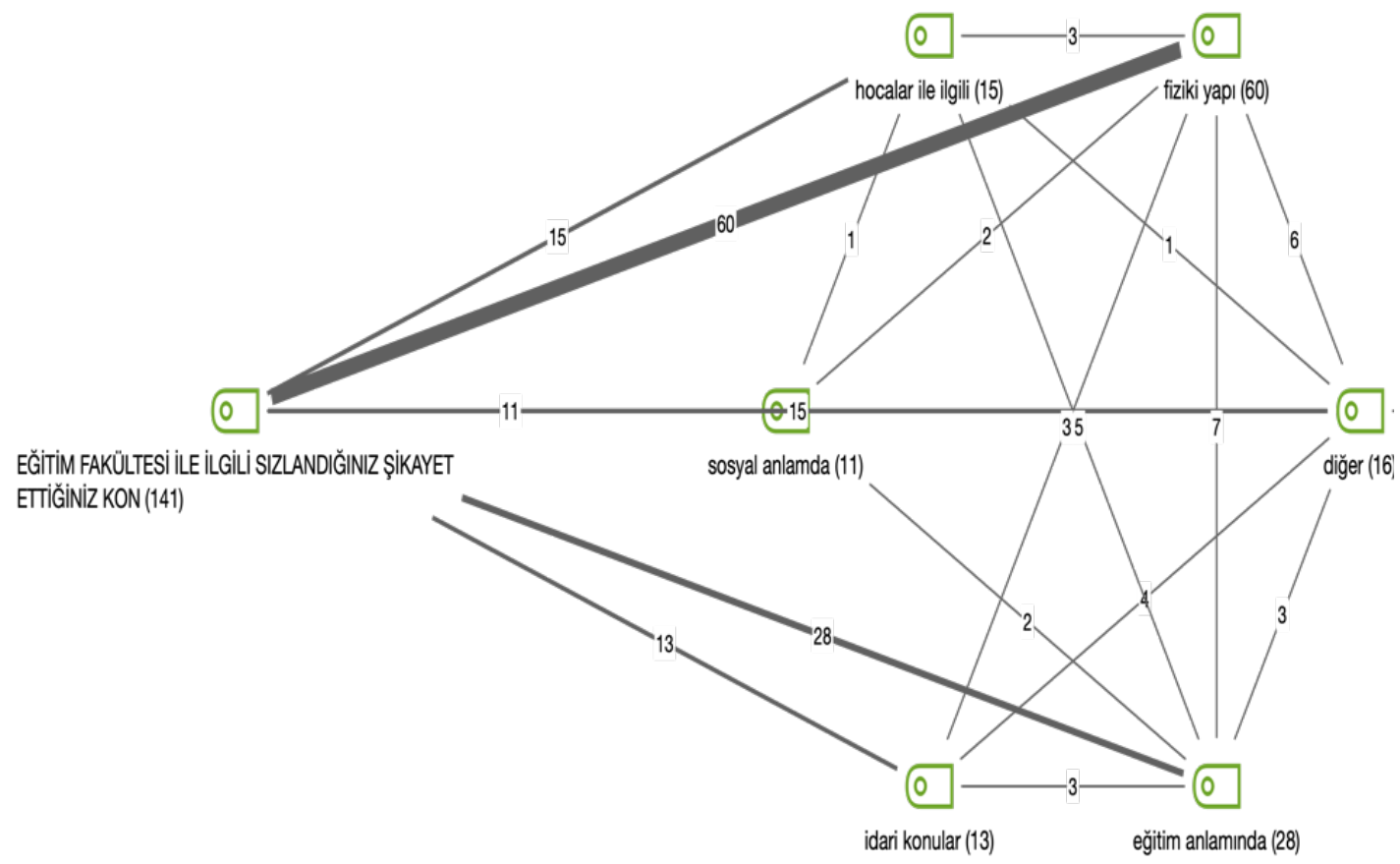


Kod birlikte oluşturma modeli incelendiğinde eğitim fakültesinde fiziki yapıdan şikayetçi olan 60 öğretmen adayının 3 tanesinin aynı zamanda hocalar ile ilgili konulardan da sızlandığı görülmektedir. Eğitim anlamında şikayetçi olan 28 kişinin 3 tanesinin, idari konulardan sızlanan 13 kişiden 3'ü olduğuna yine Şekil 7'den ulaş1lmaktadır.

Araştırma kapsamında katılımcıları EF'de mutlu eden ilk üç şey de sorulmuştur. Katılımcıların kendilerini mutlu eden ilk üç şeye ilişkin bulguları tablo 24 'de verilmiştir.

Tablo 24. Katılımcıları eğitim fakültesinde mutlu eden ilk üç şey

\begin{tabular}{lcc}
\hline Mutlu eden ilk üç şey & f & $\%$ \\
\hline Öğretim elemanlar & 157 & 34.7 \\
Lokasyon & 124 & 27.4 \\
Kantin & 179 & 39.5 \\
\hline Toplam & 453 & 100 \\
\hline
\end{tabular}

Katılımcıların belirttikleri görüşler doğrultusunda eğitim fakültesinde öğretmen adaylarını en çok mutlu eden ilk şeyin öğretim elemanları olduğu Tablo 24'de görülmektedir. Öğretmen adayları, eğitim fakültesinde kendilerini mutlu eden 2. Şeyin fakültenin konumu (lokasyon) (f:124) ve 3. Şeyin ise kantin (f:179) olduğunu belirtmişlerdir.

Araştırmada elde edilen genel bulgulara göre, öğretmen adayları tarafından "eğitim fakültesi” kavramına ilişkin toplam 150 adet geçerli metafor üretilmiş ve bu metaforlar; 9'u olumlu, 4'ü olumsuz olmak üzere13 kavramsal kategori altında toplanmıştır. Eğitim Fakültesini tanımlamada kullanılan metaforlar ve bu metaforların ait oldukları kategoriler ile kategorilere dair frekans ve yüzde değerleri Tablo 25 'te verilmiştir;

Tablo 25. Eğitim fakültesiyle ilgili metaforların genel dağılımına ilişkin bulgular

\begin{tabular}{lll}
\hline Eğitim Fakültesi... Benzer & $\mathrm{f}$ & $\%$ \\
\hline Olumlu & 104 & 73.76 \\
- Geliştiren-süreç olan bir yer & 31 & 21.99 \\
• Eğitim ve öğretmenliğin temeli olan bir yer & 20 & 14.18 \\
- Ev-yuva olan bir yer & 17 & 12.05 \\
- Aydınlanılan-ufak açan bir yer & 15 & 10.64 \\
- Amaçlara ulaştıran ve biçimlendiren bir yer & 15 & 10.64 \\
- Yol gösteren-yönlendiren bir yer & 11 & 7.80 \\
- Çalışma gerektiren bir yer & 10 & 7.09 \\
- Vazgeçilmez bir yer & 9 & 6.38 \\
- Mutluluk veren bir yer & 5 & 3.55 \\
- Olumsuz & 31 & 21.99 \\
- Karmaşı ve değişiklik gösteren bir yer & 16 & 11.35 \\
- Liseye benzeyen bir yer & 7 & 4.96 \\
- Zorlayici-kuralcı bir yer & 6 & 4.26 \\
- İsslevsiz bir yer & 5 & 3.55 \\
- Bilmiyorum & 6 & 4.26 \\
\hline Toplam & 141 & 100 \\
\hline
\end{tabular}

"Eğitim fakültesi.... benzer" sorusuna yönelik olarak öğretmenlerin verdikleri cevaplar olumlu görüşler ve olumsuz görüşler altında toplanmıştır. Olumlu şekilde düşünüp bir metafor oluşturan 104 öğretmen adayı, olumsuz yargıya varan ise 31 öğretmen adayı olduğu görülmektedir. Tablo 64 İncelendiğinde olumlu metaforlar üreten 104 katılımcıdan 31 tanesi eğitim fakültesinin geliştiren- süreç olan bir yer olduğunu, 20'si aydınlanılan- ufuk açan bir yer olduğunu, 15 tanesi amaçlara ulaştıran- şekillendiren bir yer olduğunu, 11'i yol gösteren- yönlendiren bir yer olduğunu, 10'u çalışma gerektiren, 9'u vazgeçilmez bir yer olduğunu ve 5 katılımcı ise mutluluk veren bir yer olduğuna ilişkin metaforlar üretmiş̧ir.

Tablo 64'e göre olumsuz metaforlar üreten 31 katılımcıdan 16 tanesi eğitim fakültesinin karmaşık ve değiş̧iklik gösteren bir yer olduğunu, 7'si liseye benzeyen bir yer, 6 tanesi zorlayıcı- kuralcı bir yer olduğunu ve 5 katılımcı ise işlevsiz bir yer olduğuna ilişkin metaforlar üretmiştir.

Olumlu kategoriye yönelik metafor üreten öğretmen adaylarından geliştiren-süreç olan bir yer kategorisinden bahseden bazılarının görüşleri şu şekildedir:

k.10: Tohum gibidir. Çünkü hepimiz oraya tohum olarak giriyoruz fidan olarak çıkyyoruz. Meslekte ilerledikçe yavaş yavaş ağaca dönüşüyoruz.

\section{k.12: Ĕ̌itim fakültesi yol gibidir çünkü ögretmen adaylarına ögretmenlik becerileri kazandırır}


k.15: Ăgaç, her zaman insanı geliştirir.

k.23: Hayat gibidir. Çünkü burada gerçekten hayatın içinden şeyler ögreniyoruz ve insan psikolojisi çocuk psikolojisi açısından kendimizi daha çok geliştirme firsatımız oluyor.

k. 67: Çiçek gibidir çünkü çiçeği suladığımızda büyür ve gelişir çevresine koku saçar. Eğitim fakültesinde bulunan öğrencilere de bilgiler aktarıldı̆̆ zaman gelişir ve çevresine bilgi saçar.

k.71: A ğaca benzetirim çünkü oda hep gelişir

k.102: Anne gibidir büyütür olgunlaştırır mezun eder

k.111: Kitap gibidir çünkü hocalarımdan öğrendiklerim beni çok geliştirdi. Sadece teorik değil günlük yaşantım için de bana kattıkları çok şey var.

k.117: Hayatta hazırlanacağınız yer gibidir. Çünkü zor olan bir sürü süreç ve sınavdan başarıyla ya da başarısızlıkla çıkarız hayatta da başımıza bir sürü olay gelir ve onları aşmak için gerekli azmi aslında bir sınava çalışırken elde ettiğimiz azimle yeneriz.

k.140: Ĕ̆itim Fakültesi çınar ă̆acına benzer çünkü sürekli büyür ve uzun yıllar yaşar.

Olumlu kategoriye yönelik metafor üreten öğretmen adaylarından ev- yuva olan bir yer kategorisinden bahseden bazılarının görüşleri şu şekildedir:

k. 6: Eve benzer. Çünkü bazen şükredersin bazen gitmek istersin ama yine de çoğunlukla kendini iyi hissedersin.

k.58: Yuva gibidir. Sartp sarmalar

k.63: Yaşadı̆̆ımız ev gibidir. Çünkü evimizde ailemizin bize öğrettiklerinin devamı niteliğindedir.

k.65: EF aileye benzer. Çünkü orada da sınıf arkadaşlarınla ve özellikle bazı hocalarla aile gibi oluruz. Kendimizi güvende hissederiz

k.68: Ĕ̆itim fakültesi ev gibidir. Çünkü her öğrenci bir tuğladır. Ĕ̆itim fakültesinde öğrenciler ne kadar bilimsel, sosyal çalışmalar yaparsa; fakülteden mezun olduklarında gelecek nesilleri yetiştirecek ve böylece gelecek nesillerin temelleri să̆lam olmuş olacaktır.

k.94: Ĕ̆itimin fakültesi ikinci evimiz gibidir çünkü sosyal hayatta etkili iletişim kurmak için gerekli olan görgü, bilgi ve becerileri orada ediniriz.

k.108: Ĕ̈itim Fakültesi sıcak bir yuva gibidir. Çünkü sınıf arkadaşlarımız, fakültedeki diğer öğrenciler, öğretmenlerimiz çok kaliteli ve sıcak insanlar. Ortama alıştıktan sonra kendini gerçekten oraya ait hissediyorsun...

Olumsuz kategoriye yönelik metafor üreten öğretmen adaylarından karmaşık- değişiklik gösteren bir yer kategorisinden bahseden bazılarının görüşleri şu şekildedir:

k.18: Bozuk tarla gibi yapıldı̆̆ından beri bir türlü düzenleme yapılmadı

k.22: Eskişehirspor gibidir çünkü bize mutluluğu haram eder kötü anıları hatırlatır ayrıca kavuşamayız

k.26: Hastaneye karışık ve kötü

k.78: Bir dershane havası var herkes kendi işine odaklanmış kimse kimsenin ne yaptığını umursamıyor

k.82: Eğitim fakültesi bir şans oyununa benzer çünkü eğitim sistemi ve politikaları her an değişebilmektedir.

k. 86: Şirket gibi. Çünkü okul dediğin yer karşıdan bakınca belli olur. Modern bir şey inşa edelim demişler ama orasının okul olduğunu unutmuşlar sanki. Fiziksel olarak bana hiç hitap etmiyor. Ruhsuz bir yapı. Şirketler de öyle. İ̧eride samimiyet yok, bir ruh yok. Herkes birbiriyle rekabet içinde ama ĕgitimde rekabet olmamall, kazanan-kaybeden olmamalı. Öğrenen olmalı. Bizim okul da bana şirket gibi geliyor. Maalesef ki.

Araştırmada katılımcılara EF'de yöneticileri ne kadar tanıdıkları da sorulmuş, bulgular tablo 26'da verilmiştir. Katılımcıların yöneticileri tanıma durumlarına yönelik belirttikleri görüşler doğrultusunda ana bilim dalı başkanı (f:120) ve bölüm başkanını (f:123) tanıdıkları buna karşın dekan ve yardımcılarını (f:78) tanımadıklarını ifade ettikleri belirlenmiştir. Öğretmen adayları yöneticilerin odalarının nerde olduğunu (f:80) ve görev dağılımlarını (f:119) bilmediklerini belirtmişlerdir. Katılımcıların bölüm sekreterinin adını bildikleri (f:89) ancak fakülte sekreterinin adını bilmedikleri (f:102) Tablo 26'da görülmektedir. 
Tablo 26. Katılımcıların EF yöneticilerini tanıma durumları

\begin{tabular}{lcc}
\hline & $\mathrm{f}$ & $\%$ \\
\hline Ana bilim dalı başkanının adını soyadını bilme durumu & & 85.1 \\
Evet & 120 & 14.8 \\
Hayır & 21 & 87.2 \\
Bölüm başkanının adını soyadını bilme durumu & 123 & 12.7 \\
Evet & 18 & 44.6 \\
Hayır & & 55.3 \\
Dekanın ve yardımcılarının kim olduklarını bilme durumu & 63 & 43.3 \\
Evet & 78 & 56.7 \\
Hayır & & 15.6 \\
EF yöneticilerinin odalarının nerede olduğunu bilme durumu & 61 & 84.3 \\
Evet & 80 & 63.1 \\
Hayır & & 36.8 \\
Eğitim fakültesi yöneticilerinin görev dağılımlarını bilme durumu & 22 & 27.6 \\
Evet & 119 & 72.3 \\
Hayır & & 100 \\
Bölüm sekreterinin adını bilme durumu & 89 & \\
Evet & 52 & \\
Hayır & & \\
Fakülte sekreterinin adını bilme durumu & 39 & 102 \\
Evet & 141 & \\
Hayır & & \\
\hline Toplam & & \\
\hline
\end{tabular}

\section{Tartışma ve sonuç}

$\mathrm{Bu}$ araştırmada semboller üçe ayrılarak incelenmiştir. Bunlar; fiziksel, sözel ve işlevsel sembollerdir. Örgütsel yaşamda var olan semboller; örgütlerin logoları, mimarisi, eşyalar gibi fiziksel semboller, örgütte kullanılan dil, metaforlar, mizah ve anlatılan hikayeler, efsaneler, kahramanlar gibi sözel semboller ve örgütte düzenlenen törenler ve seremoniler gibi işlevsel semboller olarak karşımıza çıkmaktadır (Özoğlu, 2015). Araştırmada elde edilen nitel veriler bu doğrultuda sonuçlara dayalı olarak ele alınmıştır. Araştırmanın nitel boyutundan elde edilen sonuçlara göre;

Eğitim fakültesinin, öğretmen adaylarının beklentilerini genel anlamda karşıladığını ve bunu da hocalar ve eğitim açısından karşılamasıyla ilişkilendirdikleri sonucuna ulaşılmışııı. Katılımcıların çoğu eğitim fakültesinin sahip oluğu fiziksel yapıyı açıkça bildiklerini, eğitim fakültesinin rengini, kat sayılarını ve giriş kapılarının nerede ve kaç adet olduğunu bildiklerini ifade etmişlerdir. Katılımcılar fakülte de bulundukları zaman dilimi içerisinde en çok koridorlarda bulunduklarını ve sınıfların fiziksel düzenlemelerinden de memnun olduklarını söylemişlerdir. Eğitim fakültesinin misyon ve vizyonun, fakültenin web sitesinde yazdığı konusundaki fikir birliği sağlayan katılımcılar, eğitim fakültesinin misyonunu ve vizyonunun, öğretmen yetiştirme içeriğini yansıttığını ifade etmişlerdir. Katılımcılar eğitim fakültesinin amblemini eğitim ile ilişkili bulduklarını fakat "eğitim fakültesinin logosunun ne olduğu bilmediklerini ifade etmişlerdir. Öğretmen adaylarının eğitim fakültesi web sitesini kullanma sıklıklarına göre dağılımlarına yönelik bulgular incelendiğinde fakültenin web sitesini sadece duyurular için kullandığı görülmüştür. Katılımcıların tamına yakını eğitim fakültesi dekan ve dekan yardımcılarının ve bölüm başkanlarının odalarının nerede olduğunu bilmediklerini ifade etmişlerdir.

Örgütsel kültürün fiziksel sembolleri olarak, mimari özellikleri, çalışma yerlerinin düzenlenmesinde kullanılan eşyalar, araçlar, gereçler, arabalar, teknoloji, kıyafetler, etiketler, logolar, amblemler, rozetler, posterler sayılabilir. Örgütlerde, özellikle yönetici odalarının bulunduğu yerler, bunların düzenlenişinde kullanılan nesneler, yöneticilerin arabaları, bunların renkleri, statü sembolleri arasında yer alır (Şişman, 2002). Buradan hareketle katılımcıların eğitim fakültesinin fiziksel sembolleri açısından benimseme durumlarının yetersiz olduğu yorumu yapılabilir. Sadece fiziksel özelliklerin ve mimari özelliklerin örgüt üyeleri tarafindan bilinmesi fiziksel sembollerin içselleştirilmesi adına yeterli değildir. Misyonun bilinmemesi, eğitim fakültesi logosunun ne olduğunun bilinmemesi ve web sitesinin sadece duyuru amaçlı kullanılması örgütsel açıdan kültürel olarak öğrencilerin zayıf bir fakülte kültürüne sahip olduklarını göstermektedir.

Katılımcının çoğu eğitim fakültesinde hayran oldukları, kendilerine rol model olarak gördükleri, kendilerini motive eden öğretim elemanlarının olduğunu belirttikleri sonucuna ulaşılmıştır. Katılımcıların çok azı eğitim fakültesinde hayran oldukları, kendilerine rol model olarak gördükleri, kendilerini motive eden her hangi bir öğretim 
elemanının olmadığını ifade etmiştir. Katılımcıların çoğu bulundukları fakültede öğretim elemanlarıyla rahatça iletişim kurabildiklerini ifade etmişlerdir. Katılımcıların iletişime geçme şekillerine bakıldığında çoğunluğun öğretim elemanları ile mail ile iletişim kurduğu, iletişime geçme nedenleri olarak ise ödevler ve ders konusunda olduğu belirtilmiştir.

Araştırma bulgularına göre katılımcıların, eğitim fakültesinde kendilerini motive eden, hafızalarına kazınan bir olay olmadığını belirttikleri sonucuna ulaşılmıştır. Katılımcıların çoğu eğitim fakültesine özel anlatılan bir hikâye veya efsane ya da özel bir dil olmadığını belirttikleri sonucu elde edilmiştir. Örgütlerin doğuşunda ve yaşamını sürdürmelerinde dil hayati bir rol oynar. Üyeler, dile yönelik çeşitli sözcük dizileri, kodlar, işaretler, semboller, metaforları kullanarak kendi gerçekliklerini tanımlarlar. Dilin temelini, anlamlı semboller oluşturmaktadır. Dil sayesinde iletişim kurar, başkalarının rollerini alabilir, kendimizi ifade edebilir ve zihnimizde her türlü düşünme aktivitesini gerçekleştirebiliriz (Özoğlu, 2015). Carlson (2012) da yaptığı araştırmada örgüt üyeleri arasında oluşturulan dilin önemi üzerinde durmuştur.

Eğitim fakültesinde öğretmen adayları kendilerini mutlu eden ilk üç şeyin; öğretim elemanlar, lokasyon ve kantin; mutsuz eden ilk üç şeyin ise okulun fiziki donanımı, sınıfların donanımı ve etkinlikler olduğunu ifade etmişlerdir. Buradan da öğretmen adaylarının bulundukları eğitim fakültesinde en çok sızlandıkları durumun fiziki yapı olduğu sonucuna ulaşılmıştır. Öğretmen eğitiminin niteliğini olumsuz etkileyen unsurlar arasında Eğitim Fakültelerindeki fiziksel olanakların yetersizliğinin yer aldığını yaptı̆̆ı araştırmalar ile ortaya koyan YÖK (2007a), Öğretmen Yetiştirme ve Eğitim Fakülteleri (1982-2007) raporunda da vurguladığı üzere, çoğu Eğitim Fakültesinde fiziki imkanların yetersiz olduğunu ifade etmiştir. Eğitim Fakültelerinde alt yapı eksiklerinin olduğu yapılan diğer araştırmalarda da ortaya konmaktadır (Dursun, 2013; Yanpar Yelken vd., 2007)

Katılımcıların eğitim fakültesinin yöneticilerine ilişkin görüşleri oldukça ilgi çekicidir. Katılımcıların tamına yakını eğitim fakültesi dekan ve dekan yardımcılarının kim olduklarını, görev tanımlarını ve odalarının nerede olduğunu bilmediklerini ifade etmişlerdir. Bununla beraber katılımcıların çoğu bölüm ve ana bilim dalı başkanlarının isimlerini bildiklerini fakat odalarının nerede olduğunu bilmediklerini ifade ettikleri görülmüştür. Üniversitelerde akademik teşkilat yönetmeliğine göre, dekanın görevleri, fakülte kurullarına başkanlık etmek, fakülte kurullarının kararlarını uygulamak ve fakülte birimleri arasında düzenli çalışmayı sağlamak, her öğretim yılı sonunda ve istendiğinde fakültenin genel durumu ve işleyişi hakkında rektöre rapor vermek, fakültenin ödenek ve kadro ihtiyaçlarını gerekçesi ile birlikte rektörlüğe bildirmek, fakülte bütçesi ile ilgili öneriyi fakülte yönetim kurulunun da görüşünü aldıktan sonra rektörlüğe sunmak, fakültenin birimleri ve her düzeydeki personeli üzerinde genel gözetim ve denetim görevini sürdürmek, kanun ve yönetmeliklerle kendisine verilen diğer görevleri yapmak olarak sıralanmıştır. Bu noktada her dekan en az iki dekan yardımcısı ve bir fakülte sekreteri ile üzerine düşen yükümlülükleri yerine getirmektedir. Öğrencilerin üst yönetimi tanımaması, görev dağılımlarını bilmemesi oryantasyon etkinliklerinin zayıf olduğunu göstermektedir. Bölüm ve anabilim dalı başkanlarının isimlerinin bilinmesi işlevsel olarak ders programları, sınav programları ya da yapılan duyurularda imza ve ismin yer alması nedeni ile daha akılda kalıcı olmaktadır. Bunun yeterli olmadığı düzenli aralıklarla öğrenci ve yöneticilerin bir araya gelerek gerek öğrenci sorunları gerekse fakülte ile ilgili istek ya da varsa şikayetlerin dinlenmesi fakülte kültürünün oluşmasında dinamik bir yapı oluşturmaktadır. Manevi olarak kendini fakülteye ait hisseden bir öğrenci fakülte kültürüne daha kolay adapte olabilmektedir.

Katılımcıların çoğu fakülte sekreterinin ismini bilmedikleri fakat bölüm sekreterinin ismini bildiklerini ifade etmişlerdir. Fakülte genelinde her türlü işleyiş, fiziki mekânların kontrolü, memurların işleyişinin denetimi ve her türlü yazışma görevlerini yerine getirmekle yükümlü olan kişi fakülte sekreteridir. Bölüm sekreteri ise bölüm ve anabilim dalı içindeki bölüm başkanı ya da ana bilim dalı başkanının kendisine verdiği işi yapmakla yükümlü, öğrencilerle daha çok bir arada bulunan öğrencilerin dilekçe ve akademik sorunlarla ilgili başvurduğu yetkilidir. $\mathrm{Bu}$ nedenle bu sonuç şaşırtıcı bir sonuç olmamakla birlikte fakülte üst yönetiminin örgütsel kültürü oluşturabilmesi adına dikkate alması gereken yapılardan birinin varlığına dikkati çekmektedir.

Araştırma sonuçlarında katılımcılardan çoğunluğunun eğitim fakültesinde herhangi bir etkinliğe katılmadı̆̆ görülmektedir. Örgütlerde düzenlenen ritüeller ve seremoniler, işlevsel semboller arasında yer alır. Bunlara katılım örgütteki bireylerin kendilerini örgüte ait olmaları be bağlı olmalarını sağlar. Araştırmadan elde edilen bu sonuç işlevsel semboller olarak eğitim fakültesinin sahip olduğu örgütsel kültürüm bu noktada zayıf olduğunu göstermektedir. Trice, Belasco ve Alutto (1969) yaptıkları araştırmada örgütsel davranışın anlaşılmasında seremonilerin etkililiği üzerine durmuş, bireylerin değer, norm, tutum ve beklentilerinin sistemi destekleyecek şekilde olumlu olması yönünde seromoni ve etkinliklerin ne kadar önemli olduğunu ifade etmiş̧tir. 
"Eğitim fakültesi.... benzer" sorusuna yönelik olarak son sınıf öğrencilerinin verdikleri cevapların çoğunun olumlu görüşler altında toplandığı görülmüştür. Öğretmen adaylarını göre eğitim fakültesi süreç içinde insanı geliştiren, eğitim ve öğretmenliğin temeli olan, aydınlatan insanları amaçlarına ulaştıran bir yer olarak tanımlanmaktadır. Metaforlar, alışılmışı acayip, acayip olanı alışııış yapan ifadelerdir. Metaforlar karmaşık konuları, bizim tutumlarımızı ve eylemlerimizi etkileyen anlaşılabilir imgelere sığdırır. Metaforlar, önemli kültürel artifaktlar olup Greenfield'in de belirttiği gibi insan yaşamına anlam katan ve merkezi bir yer teşkil eden değerler ile yakından ilgilidir (Bates, 2001). Bu açıdan bakıldığında okul yaşamında bireylerin bilinçli ya da bilinçsiz şekilde kullandıkları metafor, okulda yerleşik kültürün temellerini açığa çıkartma da faydalı olabilir.

Her örgüt ortak bir tarih, kimlik ve bütün üyelerini birleştiren bir yapıya sahiptir. Örgütsel kültür, örgüt üyelerinin örgütsel etkinlikler ve bunların sonuçların ilişkin yorumlar taşır. Bu yapı, değerler ve tutumlar, özel örgütsel bir dil, sosyal ve mesleki kurallar, ortak bir tarih, örgüt felsefesi, hikayeler, masallar, kahramanlar gibi öğelerden oluşur (Çelik, 2012). Örgüt üyeler örgütün temel değerlerini ne kadar benimser ve bu değerlere ne kadar bağlanırsa, kültür de o kadar güçlenir. Güçlü bir örgüt külttürüne sahip olmak bir bütün adına örgütsel başarı için vazgeçilmez bir olgudur. Bu nedenle eğitim örgütlerinin başarısında en önemli faktörlerden birisi de okul kültürüdür. Tüm eğitim örgütlerinde olduğu gibi üniversitelerde de güçlü bir örgüt kültürü yapısı bulunmaktadır. Üniversite külttürü farklı bir örgütsel kültür yapısını gerektirmektedir. Bunun nedeni olarak üniversite sürecinin temelinde örgüt kültürünün yer almasıdır (Salonda, 2008). İnançlar, değerler ve örgüt kurucularının varsayımları ile oluşan örgüt kültürü tüm örgüt üyeleri tarafindan paylaşılan bir yapı olarak devamlılığı sağlar. Eğitim örgütlerinde kültürden beklenen alt kültürler arası iş birliği sonucu oluşan dinamik bir yapıdır. Özellikle yöneticiler, iş birliği külttürünü yaratmada kilit bir role sahiptir. Güç ve sorumluluğun paylaşılması, alt kültür gruplarının yarattığı sembol ve ritüellerin varlığı ve bunlardan yöneticilerin faydalanabilmesi gibi uygulamalar örgütsel kültürü güçlendirir (Campo, 1993). Hamm (1993) yükseköğrenim kurumlarının kültürel etkinliklerini öğretim üyelerinin ve öğrencilerin moral özelliklerine, öğrenci gelişimine ve dış çevre ilişkilerine bağlamaktadır. Öğrenci alt kültürü ve öğretim elemanları alt kültürü ile oluşan akademik kültürde bu araştırma da özellikle öğrenci alt kültürü ele alınmıştır. Demografik özelliklere göre karmaşık, sosyal değişime açık olan bu alt kültür yapısı, arkadaş yapısı ile şekillenen duygu ve manevi değerlerin ön planda olduğu bir yapı ile oluşur. Kampüs kültürü olarak da isimlendirilen bu yapıda, geniş anlamda bir öğrenci kültürü ve arkadaş ortamında beliren çevresini algılamasını şekillendiren değerler, inançlar, tutumlar, törenler ve bazı faaliyetler bütünü görülebilir (Erdem ve İşbaşı, 2001).

\section{Yazarların katkı oranı beyanı}

S. Güven ve M. Uçar makalenin veri toplama, veri analizi, raporlaş̧ırma ve diğer aşamalarından eşit düzeyde sorumlu olduğunu beyan ederler.

\section{Çıkar çatı̧̧ması}

Bu çalışmada yazarlar tarafından herhangi bir çıar çatışması belirtilmemiştir.

\section{Etik kurul onayı}

$\mathrm{Bu}$ araştırma T.C. Çanakkale Onsekiz Mart Üniversitesi Lisansüstü Eğitim Enstitüsü Etik Kurulunun 04.05.2020 tarih ve 4/2020/72 kararı ile etik açından uygun bulunmuştur. Tüm sorumluluk yazarına aittir.

\section{Kaynakça}

Bates, RJ (2001). Eleştirel Teori Açısından Eğitim Yönetimi (Çev.: Selahattin Turan, Mehmet Şişman). Kuram ve Uygulamada Eğitim Yönetimi, 28, 573-592.

Becerikli, S. Y. (1999). Örgüt kültürü oluşumunda örgüt içi iletişimin rolü. Ankara: Yayınlanmamış Yüksek Lisans Tezi, (Ankara Üniversitesi Sosyal Bilimler Enstitüsü).

Cambo, C. (1993). Collaborative school cultures: How principals make a diffrance, School Organization, 13 (2).

Carlson, E. (2012). Precepting and aymbolic interactionism- a theoretical look at preceptorship during clinical practice. Journal of Advanced Nursing, 69(2), 457- 464. DOI: 10.1111/j.1365-2648.2012.06047.

Çelik, V. (2000). Okul kültürü ve yönetimi. Ankara:Pegem Yayıncılık.

Çelik, V. (2012). Okul kültürü ve yönetimi. (5. Baskı) Okul kültürü ve yönetimi. Ankara:Pegem Yayıncılık.

Davey, L. (2009). The Application of Case Study Evaluations. Elementary Education Online, 8(2), ç:1- 3.

Denzin, N. K. \& Lincoln, Y. S. (Eds) (1994). Handbook of Qualitative Research. Thousand Oas, CA: Sage Publications.

Dinçer, Ö. (1992). Stratejik yönetim ve işletme politikası, İstanbul:1992. 
Dursun, F. (2013). Bilişim teknolojileri öğretmen yeterliklerinin ögretim elemanı, öğretmen adayı ve öğretmen görüşlerine göre değerlendirilmesi (Yayımlanmamış Doktora Tezi) Adnan Menderes Üniversitesi, Sosyal Bilimler Enstitüsü, Aydın

Erdem, F. Ve İşbaşı, J.Ö. (2001). Eğitim kurumlarında örgüt kültürü ve öğrenci alt kültürünün algılamaları. Akdeniz İI.I.B.F. Dergisi, (1), 33-57

Güçlü, N. (2003). Örgüt kültürü. Gazi Üniversitesi Sosyal Bilimler Dergisi, 23(2), 61-85.

Güney, S. (2001). Yönetim ve organizasyon, Ankara: Nobel Yayın Dağıtım.

İpek. C. (1999). Resmi ve liseler ve özel liselerde örgütsel kültür ve öğretmen ögrrenci ilişkisi (Yayımlanmamış Doktora Tezi) Ankara Üniversitesi Sosyal Bilimler Enstitüsü Ankara.

Kılıç, A.Ç. (2014). Örgüt kültürü ile ilişkili kavramlar, (Editör:Nezahat Güçlü). Ankara:Pegem Akademi Yayınları.

Nelson, D.L. \& Campbell, J.Q. (1997). Organizational behavior. West Pubishing Company.

Ouchi, William G. (1987), Teori Z: Japonların yönetim tarzı nasıl işliyor? Çev.Yakut Güneri, İstanbul: İlgi Yayıncılık

Özalp, E. ve Kırel. Ç. (2000). Örgütsel davranış (5. baskl). Eskişehir: Anadolu Üniversitesi İşletme Fakültesi Ders Kitapları Yayın No:11.

Özoğlu, E.A. (2015). Okul kültürünün sembolik açıdan çözümlenmesi: etnografik bir çalışma (Yayımlanmaış doktora tezi) Eskişehir Osmangazi Üniversitesi Eğitim Bilimleri Enstitüsü Eğitim Bilimleri Anabilim Dalı Eğitim Yönetimi Teftişi Planlaması ve Ekonomisi Bilim Dalı, Eskişehir

Peterson, K.D. and Deal, T.E. (2009). The shaping scholl culture fieldbook, (2nd edition), USA: Jossey Bass.

Sabuncuoğlu, Z. ve Tüz, M. (1998). Örgütsel psikoloji. Bursa: Alfa/Aktüel Kitapevleri.

Salonda, L.L. (2008). Exploration of a university culture:A Papaua New Guinea case study (Yayımlanmamış doktora tezi) Victory üniversitesi, Avusttralya

Schein, E. H. (2010). Organizational culture and leadership (Vol. 2). John Wiley \& Sons.

Steinhoff, Carl R. and Owens Robert G. (1989). Towards a theory of organisational culture, Journal of Educational Administration 27,3 , pp. 6-16

Şişman, M. (2002). Öğretim liderliği. Ankara: Pegem A Yayıncılık.

Taş, H. (1999). Yaratıcı örgüt kültürü ve yönetim (Yayımlanmamış yüksek lisans tezi). İnönü Üniversitesi.

Terzi, A.R. (2000). Örgüt kültürü. Ankara: Nobel Yayın Dağıtım.

Trice, H. M., Belasco, J., \& Alutto, J. A. (1969). The role of ceremonials in organizational behavior. ILRReview, 23(1), 40-51.

Unutkan, G.A. (1995). İşletmelerin yönetimi ve örgüt kültürü, Ankara: Türkmen Kitabevi.

Yanpar Yelken,T., Çelikkaleli, Ö. ve Çapri, B. (2007). Eğitim fakültesi kalite standartlarının belirlenmesine yönelik öğretmen adayı görüşleri (Mersin üniversitesi örneği). Mersin Üniversitesi Eğitim Fakültesi Dergisi, 3(2):191-215.

YDKG (2017). http://tyyc.yok.gov.tr/?pid=38, Türkiye yükseköğretim yeterlilikler çerçevesi, Öğretmen Yetiştirme ve Eğitim Bilimleri Temel Alanı Tanıtıcı Özet Bilgi

YÖK (2007). Öğretmen yetiştirme ve eğitim fakülteleri (1982-2007) (Öğretmenin Üniversitede Yetiştirilmesinin Değerlendirilmesi). Ankara: Yükseköğretim Kurulu Yayını 2007-5. 


\section{Extended abstract}

\section{Purpose}

This research is of great importance in terms of showing how much the students of the education faculty know their own faculties and how competent the administrators and lecturers are at the point of adopting the organizational culture of the faculty. The aim of the research is to reveal how well the 4th year students of the faculty of education know the faculties of education within the framework of the physical, verbal and functional components of the organizational culture.

\section{Methodology}

In the research, qualitative method was preferred in accordance with the purpose of the research, and case study was preferred as the design. Instead of generalizing in case studies, emphasis is placed on the design of studying what is best understood from the situation (Denzin \& Lincoln, 1994). In this study, in order to understand the effect of organizational culture, it was tried to reveal how much the students of the faculty of education know about the faculty of education. The aim was not to generalize, but to reveal the existing situation clearly. Thus, the resulting product will help to understand sharply what needs to be focused on in more detail for future research. In short, case studies are a way of understanding what is actually happening, collecting data in a systematic way, analyzing it, and presenting results. (Davey, 2009). The study group of the research consisted of 141 senior students studying at the education faculty of a state university, who voluntarily participated in the research.

\section{Results}

Participants associated the emblem of the faculty of education with education. It was concluded that the majority of the participants did not know the logo. The majority of the participants associated the mission and vision of the education faculty with training teachers. However, it was concluded that the majority of the participants were agreed on where the mission and vision were written on the school's website. When the frequency of communication of the participants with the instructors was evaluated, it was concluded that they only communicated about homework and the course. Considering the way in which the participants communicated with the faculty members in their faculties, it was concluded that the majority of them communicated via e-mail. It was determined that the pre-service teacher stated that the person and/or people whom the education faculty admires are the instructors. It was concluded that the participant stated that the person and/or people he saw as a role model in the faculty of education were teaching staff. It was concluded that the majority of the pre-service teachers stated that the person and/or people who motivated them in the faculty were the instructors. When the research findings were evaluated, it was concluded that the participants stated that there was no event that motivated them in the education faculty. According to the results of the research, there is no event that is engraved in their memories in the education faculty for the majority of the participants. In line with the opinions of the participants, the first three things that make teacher candidates happy in the education faculty are; It has been concluded that there are teaching staff, location and canteen. The first three things that make the participants unhappy in the education faculty are; It was concluded that the physical equipment of the school, the equipment of the classrooms and activities. "Faculty of Education.... The answers given by the teachers to the question "similar to the question" were grouped under positive and negative opinions, and most of the participants expressed their opinions on the positive category. According to the prospective teachers, the faculty of education is similar to a place that develops and has a process.

\section{Conclusion and discussion}

In this study, symbols were analyzed by dividing into three. These; physical, verbal and functional symbols. Symbols existing in organizational life; Physical symbols such as logos, architecture, and objects of organizations, verbal symbols such as the language used in the organization, metaphors, humor and stories, legends, heroes, and functional symbols such as ceremonies and ceremonies held in the organization (Özoğlu, 2015). The qualitative data obtained in the research were handled based on the results in this direction. "Faculty of Education.... It has been seen that most of the answers given by the senior students to the question of "similar to the question" were gathered under positive opinions. According to teacher candidates, the faculty of education is defined as a place that develops people in the process, is the basis of education and teaching, and enlightens people to reach their goals. Metaphors are expressions that make the ordinary strange and the strange ordinary. Most of the participants stated that they do not know the name of the faculty secretary, but they know the name of the department secretary. The person responsible for all kinds of operations, control of physical spaces, supervision of the functioning of civil servants and all kinds of correspondence throughout the faculty is the faculty secretary. Although this result is not surprising, it draws attention to the existence of one of the structures that the top management of the faculty 
should consider in order to create the organizational culture. The opinions of the participants about the administrators of the education faculty are quite interesting. Almost all of the participants stated that they did not know who the deans and vice deans of the education faculty were, their job descriptions and where their rooms were. However, it was observed that most of the participants stated that they knew the names of the heads of departments and departments, but they did not know where their rooms were. According to the regulations of the academic organization in universities, the duties of the dean are to preside over the faculty committees, to implement the decisions of the faculty committees and to ensure regular work between the faculty units, to report to the rector on the general condition and functioning of the faculty at the end of each academic year and when requested, to present the appropriation and staff needs of the faculty together with the justification. notifying the rectorate, presenting the proposal regarding the faculty budget to the rectorate after receiving the opinion of the faculty administrative board, maintaining the general supervision and control duty on the units of the faculty and personnel at all levels, and performing other duties assigned to him by laws and regulations. At this point, each dean fulfills its obligations with at least two vice deans and a faculty secretary. The fact that the students do not know the senior management and do not know the distribution of tasks shows that the orientation activities are weak. 